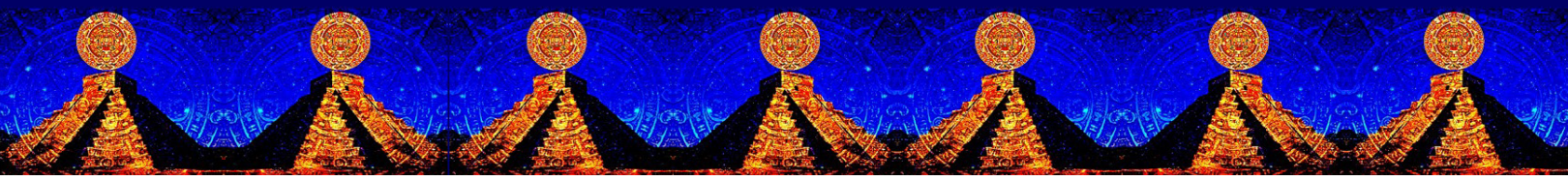

Artículo de Investigación E16A06 * Proyecto "Modelo sucesorio para la permanencia intergeneracional en empresas familiares de turismo de naturaleza y cultura". Consejo Nacional de Ciencia y Tecnología (Conacyt) - Universidad Autónoma de Querétaro. * Recibido: 27.09.2019.

Aprobado versión final: 02.02.2020. * JEL: L83, Q01. Pp. 201-230 * doi: 10.33571/teuken.v11n16a9

\title{
Especialización del ecoturismo y turismo cultural en Méjico. Evaluación del desarrollo sostenible y económico.
}

\section{Specialization of ecotourism and cultural tourism in Mexico.}

Evaluation of sustainable and economic development.

\author{
Marisol Ávila García \\ MÉJICO
}

\begin{abstract}
Resumen: La respuesta al crecimiento de la demanda turística mundial por explorar destinos alternativos requiere que los países se consoliden aprovechando sus recursos naturales y culturales con un enfoque sostenible, bajo el supuesto de que la diversificación de destinos puede tener indicadores positivos en la lucha contra la pobreza y la desigualdad social. El artículo tiene como objetivo evaluar las políticas públicas turísticas y la teoría de aglomeración en los servicios de ecoturismo y turismo cultural en Méjico, utilizando indicadores de desarrollo sostenible, salarios, empleo y coeficiente de especialización para los años censales 2004, 2009 y 2014. Se analizaron 32 regiones de Méjico, enfatizando en dos programas regionales y en la norma NMX-AA-133-SCFI-2013.
\end{abstract}

Palabras clave: turismo cultural; ecoturismo; desarrollo sostenible.

Abstract: The response to the growth of global tourism demand to explore alternative destinations requires that countries consolidate taking advantage of their natural and cultural resources with a sustainable approach in the assumption that, the diversification of destinations will have positive indicators in fighting poverty and social inequality. The aim of this paper is to evaluate public tourism policies and the agglomeration theory in ecotourism and cultural tourism services in Mexico using indicators of sustainable development, wages, employment and specialization coefficient for the 2004, 2009 and 2014 census years. The paper analyzes 32 entities from Mexico, emphasizing in two regional programs and the NMX-AA-133-SCFI-2013 standard.

Keywords: cultural tourism; ecotourism; sustainable development.

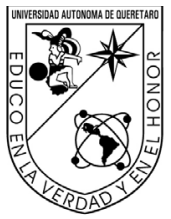

Marisol Ávila es Licenciada en Comercio Internacional, Maestra en Administración y estudiante de Doctorado en Ciencias Económico-Administrativas de la Universidad Autónoma de Querétaro. Actualmente, es estudiante becaria por el Consejo Nacional de Ciencia y Tecnología del Gobierno de Méjico (Conacyt), con actividades académicas y de investigación en la Universidad Autónoma de Querétaro y la Universidad Politécnica de Querétaro.

Contacto:advaenf@gmail.com 


\title{
Especialização em ecoturismo e turismo cultural no Méjico.
}

Avaliação do desenvolvimento sustentável e econômico

\begin{abstract}
Resumo: A resposta ao crescimento da demanda mundial de turismo por explorar destinos alternativos exige que os países se consolidem aproveitando seus recursos naturais e culturais com uma abordagem sustentável, assumindo que a diversificação de destinos terá indicadores positivos na luta contra a pobreza e desigualdade social. O objetivo desta investigação é avaliar políticas públicas de turismo e a teoria da aglomeração em serviços de ecoturismo e turismo cultural no Méjico, utilizando indicadores de coeficiente de desenvolvimento sustentável, salários, emprego e especialização para os anos censitários de 2004, 2009 e 2014. Ele analisará 32 entidades da Mexico, enfatizando dois programas regionais e o e o padrão NMX-AA-133-SCFI-2013.
\end{abstract}

Palavras-chave: turismo cultural; ecoturismo; desenvolvimento sustentável.

\section{Introducción}

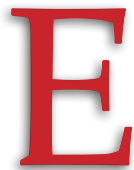

panorama del turismo a nivel mundial ha mostrado un crecimiento sostenido desde 1950 hasta la fecha. Según la Organización Mundial del Turismo (OMT), las llegadas de turistas internacionales en el mundo pasaron de 674 millones en el año 2000 a 1.235 millones en 2016, lo que configura una tendencia de la población mundial a hacer turismo internacional. La OMT mostró indicadores aceptables para el caso de Méjico. A pesar de que América del Norte creció un 0.02 en 2016 en comparación con América del Sur, que creció un 0.07, Méjico con un crecimiento del 0.09 logró atraer turistas estadounidenses favorecidos por el tipo de cambio del dólar americano. En relación con el turismo internacional, el país se posicionó en el lugar número ocho a nivel mundial en 2016 por la llegada de 32.5 millones de turistas internacionales, subiendo una posición al indicador anterior y dos posiciones en ingresos por turismo internacional, situándolo en el décimo cuarto lugar a nivel mundial (OMT, 2017a:2-6).

Para generar impactos positivos en el aumento de ingresos y nuevos empleos, así como el desarrollo de un turismo más incluyente, inteligente y responsable, la OMT considera que el turismo de naturaleza es una estrategia de alta significancia para lograr los objetivos de crecimiento sostenible propuestos por la Organización de Naciones Unidas (ONU, 2015). El segmento turístico de naturaleza es una de las modalidades más importantes de la industria turística por el alto valor adquisitivo, con tasas sostenidas del 65\% por año desde 2013; además, es un catalizador de desarrollo económico local y regional al impulsar prácticas productivas que pueden fomentar el aprovechamiento sustentable de los recursos y su conservación (SECTUR, 2017a:4-9). 
The Green Economy Report, publicado por el Programa de Naciones Unidas para el Medio Ambiente (PNUMA), y la OMT indicaron que el turismo de naturaleza y cultura están creciendo a ritmos de hasta $20 \%$ anual, entre 4 y 5 veces más que el turismo de masas. El turismo de naturaleza es un mercado creciente para los turistas internacionales, donde Méjico por la riqueza natural, cultural y ubicación geográfica tiene un activo altamente valioso que debe ser innovado y desarrollado, a partir de nuevos productos turísticos sustentables que estén relacionados con el aprovechamiento de los recursos naturales existentes (SECTUR, 2017a:10).

El artículo pretende contribuir a la evaluación de las políticas públicas turísticas y de la teoría de aglomeración en la industria de servicios turísticos de naturaleza y cultura en Méjico en la modalidad ecoturismo y cultura, utilizando indicadores de desarrollo sostenible, salarios, empleo y coeficiente de especialización.

\section{Problemática}

La Política Nacional del Turismo de Naturaleza reconoce que existe un mercado consumidor en crecimiento que demanda actividades turísticorecreacionales, deportivas con alto grado de especialización y turistas no especializados y tradicionales que realizan actividades relativas turismo de naturaleza, quienes requieren productos turísticos diversificados, especializados y competitivos a nivel mundial (SECTUR, 2017b:13). Sin embargo, los espacios naturales deben contar con una gestión que atienda los principios de la sostenibilidad donde los servicios turísticos consideren las repercusiones actuales, futuras, económicas, sociales, culturales y medioambientales para satisfacer las necesidades de los visitantes de la industria, del entorno y de las comunidades anfitrionas (SECTUR, 2017b:13).

Así mismo, la Secretaría de Turismo (SECTUR, 2017b:20) manifiesta que se requiere promover un grado de especialización integral que permita brindar servicios de calidad y competitivos para los mercados potenciales. De igual manera, diversos organismos empresariales han señalado la existencia de una problemática provocada por agentes que, sin contar con la experiencia en la materia, ocasiona la incursión de comunidades receptoras en este tipo de actividades sin el acompañamiento adecuado de las instituciones especializadas en turismo.

Las empresas de turismo de naturaleza están concentradas, principalmente, en el sureste y suroeste de Méjico, donde existen mayores comunidades indígenas. Casi todas las empresas indígenas de turismo, desde hace 
más de dos décadas, han contado con financiamiento gubernamental y apoyo de instituciones universitarias, empresas y organizaciones sociales tanto nacionales como extranjeras, como una estrategia contra la pobreza y el esquema de transferencia de recursos económicos sin retorno de efectivo (López y Palomino, 2015:102).

La principal modalidad de turismo de naturaleza financiada por el Gobierno mejicano es el ecoturismo, donde se encuentran los sectores minoritarios que ocupan el $36 \%$ del Producto Interno Bruto Turístico (PIBT) y están conformados por los subsectores de comercio, bienes y artesanías, servicios culturales, deportivos, recreativas, reserva, entre otros. En relación con la generación de empleo, estos sectores aportan el 37\% de los Puestos de Trabajo Ocupados Remunerados (PTOR) (INEGI, 2018:3-6).

En la revisión de la Política de Turismo de Méjico, la Organización de Cooperación y Desarrollo Económico (OCDE) señaló que para desarrollar un modelo turístico de mayor competitividad en el mercado del turismo global y para alcanzar mayores beneficios de desarrollo económico y social, es necesario que la actividad turística se desarrolle y articule en un marco de Política de Estado y fomentar una mayor diversificación de productos y destinos, ampliando la base de activos, promoviendo mercados turísticos de mayor valor e impulsando la conformación de clusters turísticos asociados con el desarrollo del capital natural, cultural y técnico (OCDE, 2017:13). Es necesario evaluar los beneficios económicos y sostenibles del turismo de naturaleza y cultura derivada de las políticas públicas turísticas de Méjico y su dirección hacia un enfoque de clusters o regiones propuesto por la OCDE en su estudio de revisión de la Política de Turismo de Méjico (2017) y la SECTUR (2017a; 2017b).

A partir de lo anterior, cabe indagar sobre: ¿El impacto de 35 millones de turistas del exterior que han visitado Méjico, convirtiéndolo en el octavo país más visitado del mundo en cuatro años hasta 2016 y que ha generado el $87 \%$ del PIB, ha sido positivo en el desarrollo económico del turismo de naturaleza y cultura? ¿Cuáles son los escenarios que marcan la especialización relativa en el sector del turismo de naturaleza y cultura como lo proponen las teorías de especialización? ¿Qué relación existe entre las políticas turísticas del país con el desarrollo económico del turismo de naturaleza y cultura medida por salarios, empleo y sostenibilidad? ¿Un alto cociente de ubicación en un estado de la República Mejicana en el turismo de naturaleza y cultura será bueno o malo para el ingreso regional o el empleo? ¿El ingreso regional del turismo de naturaleza y cultura dependen completamente de si un 
país se especializa en un sector con alto crecimiento externo? ¿De qué manera el desarrollo económico del turismo de naturaleza y cultura en una aglomeración local particular se modifica en relación con los cambios en la especialización a lo largo del tiempo?

\section{Investigaciones de especialización del sector turístico en Méjico}

En su investigación, Barrón y Árriola (2015:55) presentan un análisis de la actividad turística en el que identifican la estructura económica regional asociada al sector, la especialización en el empleo y los índices de productividad de Méjico enfocados al sector turístico. El resultado fue una estructura basada en las Micro, Pequeñas y Medianas Empresas (MiPyMe), donde la especialización en el empleo, la eficiencia del uso de los insumos y la productividad están condicionados por los espacios en donde se desenvuelve la actividad turística. Además, son heterogéneos en la conformación de sus estructuras económicas.

Por su parte, Oceguera, Cartillo \& Verella (2009:81) estudiaron la función de la especialización en el desempeño económico de Méjico. Los resultados indicaron que las regiones ricas son preferentemente economías de servicios; las que más crecen se especializan en la producción de manufacturas comúnmente con ingresos medios y altos; las pobres, orientan sus procesos productivos hacia actividades en recursos naturales. Con respecto al crecimiento económico, generalmente la especialización en actividades clave tiene un impacto positivo. Finalmente concluyen que el tipo de actividades que realiza una comunidad y la clase de bienes que produce son de mayor importancia para determinar su desempeño económico.

Los estudios de Pérez, Sánchez y Cuadrado (2018:216), desde una perspectiva espacial que agrupa los datos municipales del empleo en términos sectoriales y espaciales y utiliza indicadores de localización y diversidad, reflejan cómo los servicios se encuentran estructurados de manera jerárquica de acuerdo con la Teoría de Lugar Central (TLC). Los servicios con mayor productividad se encuentran en las ciudades más grandes, como la Zona Metropolitana de la Ciudad de Méjico; sin embargo, en zonas desconcentradas los servicios se encuentran en actividades industriales y turísticas.

En la especialización relativa, Kemeny \& Storper (2014:1018) sugieren que, al aumentar el tamaño de una actividad económica en una misma localidad, debería afectar positivamente la productividad, esta es la idea central de la teoría de la nueva geografía económica, que propone a 
una aglomeración de productores, como un sistema de suministro que interactúa, un sistema de correspondencia del mercado laboral local y un contexto para el intercambio de conocimiento y el derrame. Los autores consideran que los salarios son una medida para representar la productividad de las regiones al requerir mano de obra especializada en tecnología y procesos.

\section{Metodología}

La investigación es de tipo cuantitativo con enfoque transversal. Se utilizaron censos económicos e indicadores de desarrollo sostenible derivados de investigaciones del campo académico de turismo e instituciones gubernamentales o internacionales. Para analizar el desarrollo económico se tomaron indicadores censales de 32 regiones. Los indicadores económicos de empleo, salario y unidades económicas se analizaron a través del Sistema Automatizado de Información Censal (SAIC) mejicano clasificado a 4 dígitos (7121), para la actividad económica de servicios: museos, sitios históricos zoológicos y similares. Se obtuvo los datos de empresas, salarios, empleo y el Coeficiente de localización para enfatizar en los Estados contemplados en los programas regionales: pueblos mágicos, mundo maya y ruta de los dioses. Finalmente, se compararon los resultados del indicador 7 de sostenibilidad ambiental reportados por el Gobierno de Méjico.

\section{La teoría de aglomeración en el sector turístico}

Antes de explicar la teoría de aglomeración en el sector turístico es necesario comprender el concepto de aglomeración urbana. La aglomeración urbana es la concentración espacial de la actividad económica en las ciudades o la concentración en grupos industriales o en centros de empleo en una ciudad. La concentración espacial es la actividad económica, donde los factores productivos inducen un proceso acumulativo de concentración de otros mercados y actividades.

Las economías de aglomeración se clasifican como economías de localización que explican la concentración en industrias particulares en una misma localidad o economías internas que conllevan a la concentración de la producción en una única empresa, donde se aglomeran a un nivel de escala que tiene relación con el tamaño óptimo de la planta, y economías de urbanización que estudian el tamaño o la diversidad de la ciudad y sus aprovechamientos asociados a la dimensión alcanzada por una zona urbana (Manrique, 2006; Arriaga, Leyva y Estrada, 2005). 
Los modelos de la nueva geografía económica muestran que el intercambio de proveedores de insumos genera una combinación de la demanda laboral especializada y la oferta laboral, especialmente, en un contexto de industrias de alta rotación. El aprendizaje tecnológico o derrames es consecuencia de la innovación al involucrar tipos de actores distribuidos en diferentes organizaciones (Durante y Puga; Rosenthal y Strange citado por Kemeny \& Storper 2014:1006).

La teoría de encadenamientos de Hirschman (citado por Elías \& Tuma, 2009:69) pretende mostrar de qué manera y en qué momento la producción de un sector logra satisfacer el umbral o escala mínima necesaria para hacer atractiva la inversión en otro sector que este abastece (encadenamiento hacia atrás) o procesa (encadenamiento hacia adelante). Hirschaman relaciona el crecimiento con la conexión entre sectores a partir del crecimiento desequilibrado, donde el propio mercado responderá realizando las inversiones necesarias para corregir la situación de desequilibrio.

Los clusters y el turismo, según Elías \& Tuma, 2009:75, son una actividad que posee gran capacidad para producir encadenamientos con el resto de la economía. Considerando que la intersectorialidad de la actividad turística permite generar efectos multiplicadores de gran amplitud y la búsqueda de economías de escala y de aglomeración, lo que promueve la concentración geográfica o espacial tanto de las actividades productivas y de servicios como de los recursos humanos. Lo anterior coincide con Figuerola (2009) al comprender el turismo como un subsistema del cuadro económico que se integra en las participaciones de una gran parte de los subsectores de las ramas productivas, quienes dependen de la oferta de los grandes sectores económicos, clasificados como producción generada indirectamente por los gastos totales de los viajeros o influencia directa, y estos a su vez al exigir los sectores productivos de bienes y servicios que demandan las empresas que atienden a los turistas.

\section{Desarrollo sostenible}

El concepto de sostenibilidad aparece en 1972 en Los límites del crecimiento, un informe del Club de Roma, La declaración de Estocolmo, de la conferencia de la ONU sobre el Medio Ambiente Humano y el Informe Brundtland en 1987. La definición proviene del informe Nuestro Futuro Común para la Comisión de Desarrollo y Medio Ambiente de la ONU, quien definió la sostenibilidad bajo la siguiente premisa: "Está en manos de la humanidad asegurar que el desarrollo sea sostenible, es decir, asegurar que satisfaga las necesidades del presente sin comprometer la capacidad 
de las futuras generaciones para satisfacer las propias" (Brundtland citado por Díaz, Solano y Speakman, 2017:121).

En Río de Janeiro se llevó a cabo La Declaración sobre Medio Ambiente y el Desarrollo en 1992, con el objetivo de establecer una nueva alianza mundial entre los países participantes para proteger la integridad del sistema ambiental y el desarrollo mundial. De esta reunión se surge La Agenda 21 con el fin de establecer un programa de acción para implementar el desarrollo sostenible en los países a nivel mundial según las situaciones, capacidades y prioridades de los estados. De la Agenda 21 surge un instrumento metodológico con 113 indicadores que formó parte de la prueba piloto a nivel mundial por la Comisión de Desarrollo Sostenible de la ONU en los períodos de 1996 y 1999. Méjico participó en la prueba piloto y los resultados fueron publicados como Indicadores de Desarrollo Sostenible en Méjico por parte del Instituto Nacional de Estadística y Geografía (INEGI), El Instituto Nacional de Ecología (INE) y La Secretaría de Medio Ambiente y Recursos Naturales (Semarnat).

La Cumbre del Milenio de las Naciones (2000) estableció 8 objetivos de desarrollo que fueron evaluados y presentados por la ONU en el Informe 2015 de los Objetivos de Desarrollo del Milenio (ODM). En la tabla 1 se describen los ocho ODM y el resultado de su cumplimiento.

Tabla 1. Objetivos del Desarrollo del Milenio y sus resultados del informe 2015

\begin{tabular}{|c|c|c|}
\hline \multicolumn{2}{|r|}{ Objetivos } & Informe 2015 \\
\hline 1 & $\begin{array}{l}\text { Erradicar la pobreza } \\
\text { extrema y el hambre }\end{array}$ & $\begin{array}{l}\text { La población que vivía con menos de un dólar se redujo } \\
\text { de 1,926 millones a } 836 \text { millones entre } 1990 \text { y } 2015 \text {. }\end{array}$ \\
\hline 2 & $\begin{array}{l}\text { Lograr la enseñanza } \\
\text { primaria universal. }\end{array}$ & $\begin{array}{l}\text { Los niños que no asistieron a la escuela prima } \\
\text { de } 100 \text { millones a } 57 \text { millones entre } 2000 \text { y }\end{array}$ \\
\hline 3 & $\begin{array}{l}\text { Promover la igualdad } \\
\text { entre los sexos } \\
\text { y el empoderamiento } \\
\text { de la mujer. }\end{array}$ & $\begin{array}{l}\text { En los últimos } 20 \text { años las mujeres han tenido mayor } \\
\text { representación parlamentaria en casi el } 90 \% \text { de los } 174 \\
\text { países que cuentan con datos. }\end{array}$ \\
\hline 4 & $\begin{array}{l}\text { Reducir la mortalidad } \\
\text { de los niños menores } \\
\text { de } 5 \text { años. }\end{array}$ & $\begin{array}{l}\text { La tasa mundial de niños menores de } 5 \text { años ha } \\
\text { disminuido de } 90 \text { a } 43 \text { muertes por cada } 1,000 \text { niños } \\
\text { nacidos vivos entre } 1990 \text { y } 2015 \text {. }\end{array}$ \\
\hline 5 & $\begin{array}{l}\text { Mejorar la salud } \\
\text { materna. }\end{array}$ & $\begin{array}{l}\text { La tasa mundial de mortalidad materna ha disminuido } \\
\text { de } 380 \text { a } 210 \text { por cada } 100,000 \text { nacidos vivos. }\end{array}$ \\
\hline 6 & $\begin{array}{l}\text { Combatir el VIH/ } \\
\text { SIDA,la malaria y otras } \\
\text { enfermedades. }\end{array}$ & $\begin{array}{l}\text { Las personas con VIH que recibieron terapia } \\
\text { antirretroviral se incrementaron de } 0.8 \text { millones a } 13.6 \\
\text { millones entre } 2003 \text { y } 2014 \text {. }\end{array}$ \\
\hline
\end{tabular}




\begin{tabular}{|l|l|l|}
\hline \multicolumn{2}{|c|}{ Objetivos } & \multicolumn{2}{c|}{ Informe 2015} \\
$\mathbf{7}$ & $\begin{array}{l}\text { Garantizar } \\
\text { la sostenibilidad } \\
\text { del medio ambiente. }\end{array}$ & $\begin{array}{l}\text { De los 2,600 millones de personas que obtuvieron } \\
\text { acceso a fuentes de agua mejorada, 1,900 lo hicieron a } \\
\text { través de agua potable suministrada por tubería en su } \\
\text { vivienda, entre 1990 y } 2015 .\end{array}$ \\
\hline $\mathbf{8}$ & $\begin{array}{l}\text { Fomentar una alianza } \\
\text { mundial para } \\
\text { el desarrollo. }\end{array}$ & $\begin{array}{l}\text { La asistencia oficial para el desarrollo fue de 135,200 } \\
\text { millones de dólares, lo que representó un aumento del } \\
66 \% \text { entre los años } 2000 \text { y } 2014 .\end{array}$ \\
\hline
\end{tabular}

Fuente: Tomado de la ONU (citado por Díaz, Solano y Speakman, 2017).

Los ODM y el Informe 2015 reconocen que existen vacíos de información en diversas áreas de desarrollo, observan que persiste la pobreza, la desnutrición, la desigualdad de género, la brecha entre los hogares pobres y los más ricos; persiste desigualdad entre zonas rurales y urbanas, el analfabetismo, la falta de servicios básicos de salud, entre otros. Detectan que existe la necesidad de medir para conocer y diseñar estrategias para mejorar los indicadores con mayor rezago del desarrollo sostenible (Díaz, Solano y Speakman, 2017).

La ONU aprobó en septiembre de 2015 La Agenda 2030 para el Desarrollo Sostenible, en sustitución de los ODM. La Agenda 2030 presenta 17 Objetivos de Desarrollo Sostenible (ODS) que contemplan tres dimensiones del desarrollo fundamentadas en el buen gobierno: poner fin a la pobreza, proteger el planeta y garantizar que todas las personas gocen de paz y prosperidad. Los ODS contemplan 169 metas y 231 indicadores.

\section{Resultados}

\section{Ecoturismo y turismo cultural: clasificación a cuatro dígitos}

En Méjico, el turismo de naturaleza comprende todos aquellos viajes que tienen como fin realizar actividades recreativas en contacto directo con la naturaleza y las expresiones culturales, con una actitud y compromiso de conocer, respetar, disfrutar y participar en la conservación de los recursos naturales y culturales. Estos viajes se agrupan de acuerdo con el interés del turista en tres modalidades: ecoturismo, turismo de aventura y turismo rural. Estas modalidades integran actividades con características homogéneas y desarrolladas con diferentes niveles de especialización, pero orientadas a generar diferentes experiencias (Sectur, 2017a:6). 
El ecoturismo es una actividad turística basada en la naturaleza, donde la motivación principal del visitante es observar, aprender, descubrir, experimentar y apreciar la diversidad biológica y cultural, con una actitud responsable de proteger la integridad del ecosistema y fomentar el bienestar de la comunidad local (OMT, 2019:33). Por su parte, el turismo cultural es un tipo de actividad turística en la que el visitante busca aprender, descubrir, experimentar y consumir los atractivos o productos culturales, materiales e inmateriales, de un destino turístico. Estos pueden abarcar las artes y la arquitectura, el patrimonio histórico y cultural, el patrimonio gastronómico, la literatura, la música, las industrias creativas y las culturas vivas con sus formas de vida, sistemas de valores, creencias y tradiciones (OMT, 2019:31).

El enfoque económico para el estudio del turismo, de acuerdo con Figuerola (citado por Moncada, 2017:38), busca distinguir una industria de servicios como marco de referencia y subsistema del cuadro económico, que se integra en las participaciones de una gran parte de los subsistemas de los sectores o ramas productivas. Se considera apropiada la clasificación de la industria de servicios definida por el Sistema de Clasificación Industrial de América del Norte (SCIAN, 2018).

EI SCIAN (2018), en su clasificación a dos dígitos (71), describe el turismo cultural como un conjunto de servicios de esparcimiento culturales y deportivos y otros servicios relacionados que se dedican principalmente a la producción, promoción y presentación de espectáculos artísticos, culturales, deportivos y similares; a la representación y administración de artistas, deportistas y similares, y a la creación y producción, por cuenta propia, de trabajos artísticos y culturales o a proveer la experiencia técnica necesaria para realizar dichos trabajos.

Para lograr la clasificación adecuada del ecoturismo y turismo cultural, se utiliza una clasificación a cuatro dígitos (7121) que incluye a los museos, sitios, históricos y similares. En esta clasificación, la industria son las actividades dedicadas principalmente a exhibir colecciones de carácter artístico, científico e histórico de valor cultural; a hacer posible el acceso al público a edificios históricos, zonas arqueológicas y otros lugares de interés histórico; a exhibir plantas y animales salvajes vivos, y a hacer posible el acceso del público a zonas naturales y otros sitios del patrimonio cultural de la nación.

La clasificación del sector económico turístico es importante porque permite abarcar diferentes niveles de similitud de las actividades del ecoturismo y turismo cultural a cuatro dígitos, y no agregar actividades 
de dos dígitos (71) que no estén relacionadas con el turismo que acá se analiza. También evita la desagregación al examinar una clasificación a seis dígitos. En este sentido, se considera que el uso adecuado es una clasificación a cuatro dígitos (7121), lo que permite incluir actividades productivas integradas al ecoturismo y el turismo cultural. La clasificación a cuatro dígitos se hace de acuerdo con Kemeny \& Storper (2014:1009), quienes argumentan que los cuatro dígitos de la clasificación SCIAN permite resolver el problema del límite preciso en el nivel de agregación de la información.

\section{Coeficiente de localización}

En el cálculo de la especialización relativa se utiliza el coeficiente de localización como medida de la proporción de la actividad económica de ecoturismo y turismo cultural en 32 regiones de Méjico. La actividad económica a cuatro dígitos (7121), que comprende museos, sitios históricos y similares, permitirá determinar la proporción de esta actividad en el país y por región, utilizando el personal ocupado total para cada entidad federativa de Méjico. Según Boisier (1980:37), la expresión algebraica es:

$$
\frac{\mathrm{V}_{i j}}{\sum_{j} V_{i j}}: \frac{\sum_{j} V_{i j}}{\sum_{i} \Sigma_{j} V_{i j}}
$$

$\mathrm{V}_{i j}=$ Valor de $\mathrm{V}$ correspondiente al sector "i" de la región "j".

$\Sigma_{i} \mathrm{~V}_{i j}=$ Valor de $\mathrm{V}$ correspondiente al total regional.

$\Sigma_{j} \mathrm{~V}_{i j}=$ Valor de $\mathrm{V}$ correspondiente al total sectorial.

$\sum_{i} \sum_{j} \Sigma_{i j}=$ Valor de $\mathrm{V}$ correspondiente al total nacional.

En este caso, Ves el empleo de la actividad de museos, sitios históricos y similares (7221) en el estado seleccionado de Méjico; es el empleo total del estado seleccionado; es el empleo de la industria turística (museos, sitios históricos y similares) total nacional; representa el empleo total nacional. En la tabla 2 se observa la matriz de las regiones con los valores obtenidos en la industria 7221 para los 32 estados de Méjico analizados en los años censales 2004, 2009 y 2014.

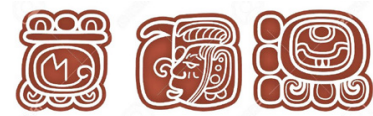




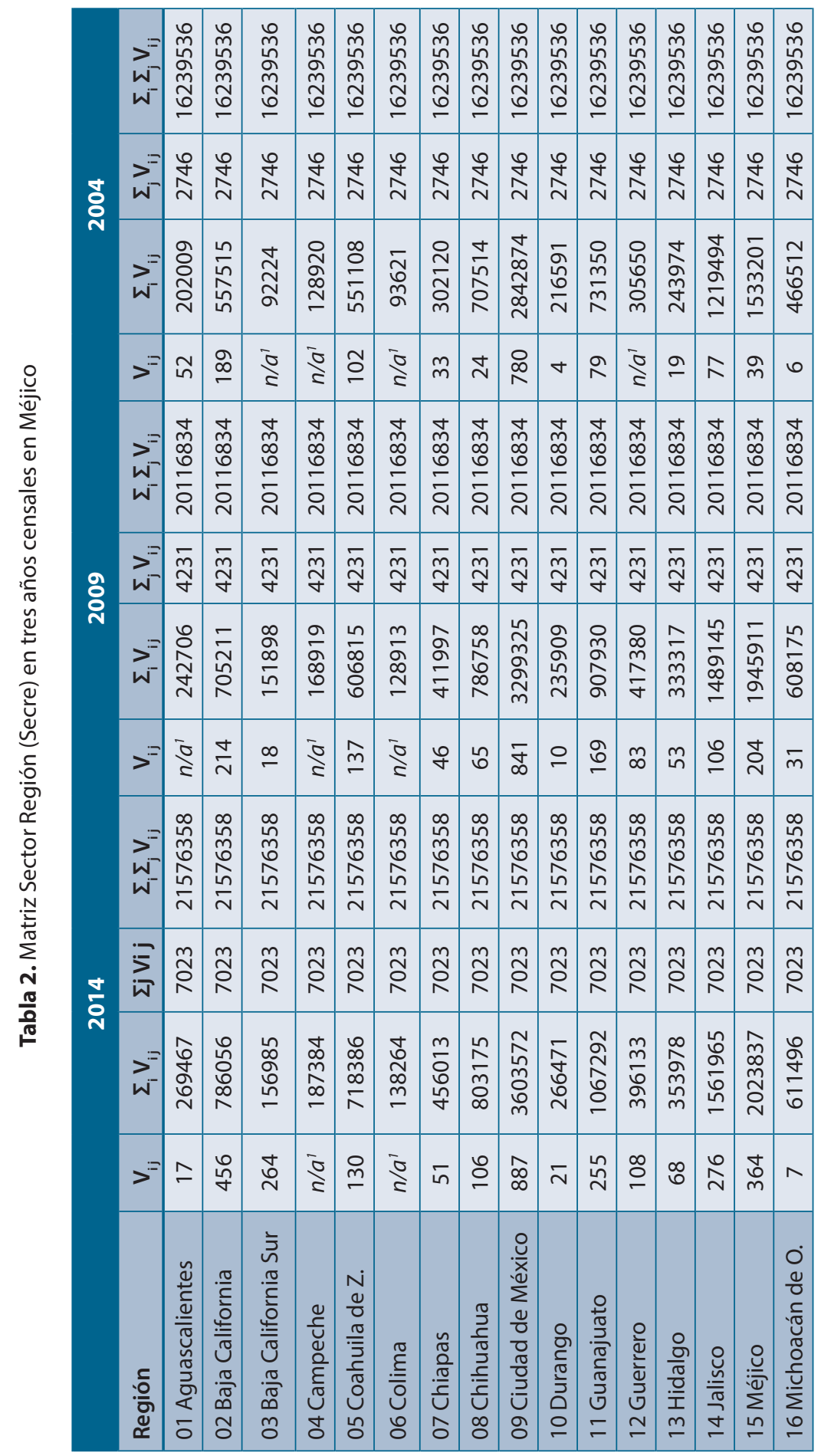




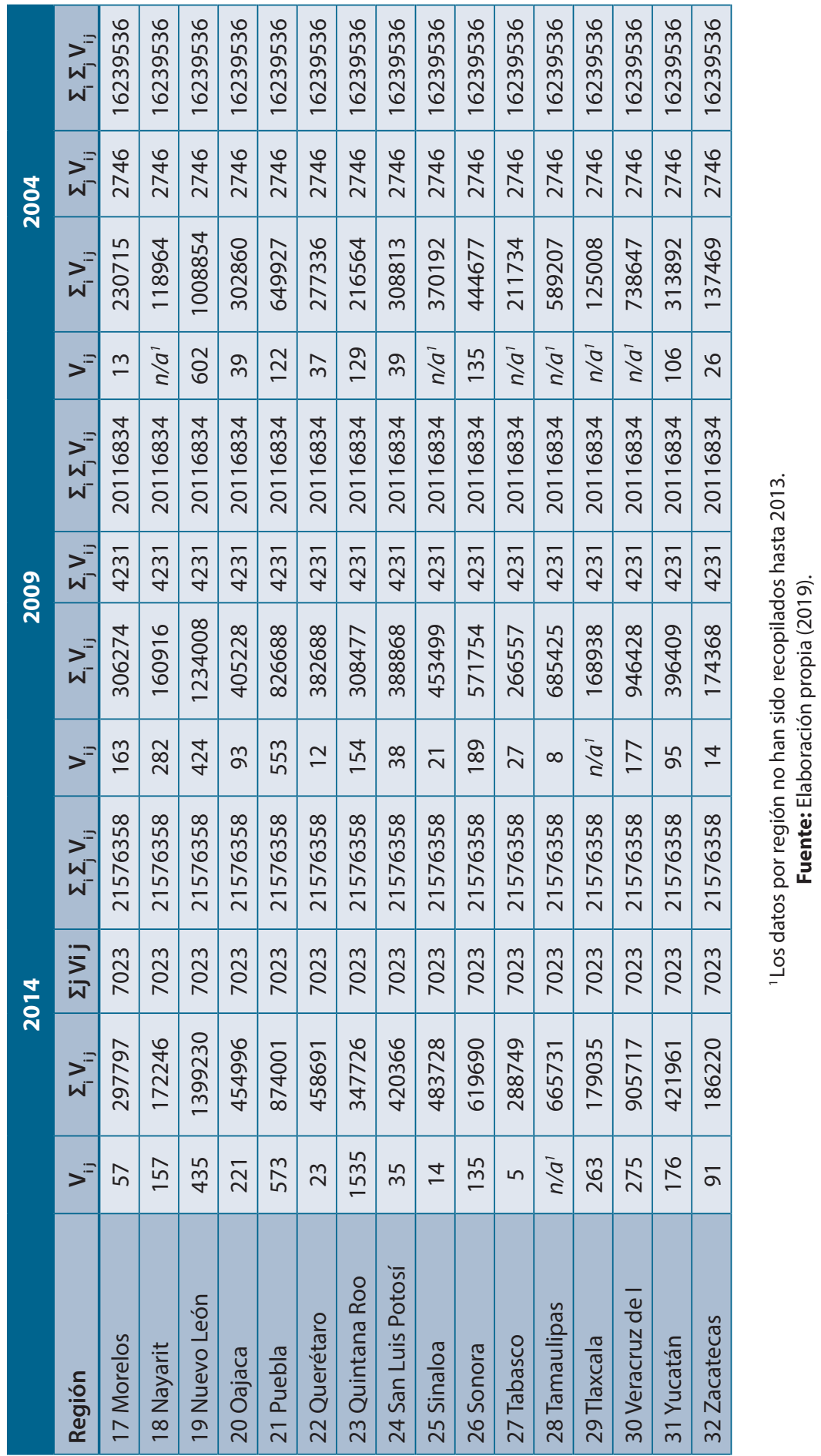


El indicador $Q_{i j}$ se expresa así: un estado de Méjico estará especializado en alguna actividad económica si su aportación, respecto al total del estado, es mayor que la aportación de ese sector a escala nacional; por lo tanto, el índice será mayor a la unidad. Por el contrario, si el $Q_{i j}$ es menor que uno, el estado no estará especializado en dicho sector. Por último, cuanto más sobrepase la unidad el valor del índice de un país en un determinado sector, mayor será su nivel de especialización relativa, siendo la especialización media a escala de los estados de Méjico seleccionados igual a la unidad uno (Rodríguez, 2005: 27-33). El coeficiente de localización de las 32 regiones en tres años censales se observa en la tabla 3.

Tabla 3. Coeficientes de localización en 32 regiones de Méjico

\begin{tabular}{|l|c|c|c|}
\hline Regiones & Qij 2014 & Qij 2009 & Qij 2004 \\
\hline 01 Aguascalientes & 0,19 & $n / a^{1}$ & ${ }^{*} 1.52$ \\
\hline 02 Baja California & $* 1.78$ & $* 1.44$ & ${ }^{*} 2.00$ \\
\hline 03 Baja California Sur & $* * * 5.17$ & $n / a^{1}$ & $n / a^{1}$ \\
\hline 04 Campeche & $n / a^{1}$ & $n / a^{1}$ & $n / a^{1}$ \\
\hline 05 Coahuila de Z. & 0,56 & $* 1.07$ & $* 1.09$ \\
\hline 06 Colima & $n / a^{1}$ & $n / a^{1}$ & $n / a^{1}$ \\
\hline 07 Chiapas & 0,34 & 0,53 & 0,65 \\
\hline 08 Chihuahua & 0,41 & 0,39 & 0,2 \\
\hline 09 Ciudad de M. & 0,76 & $* 1.21$ & $* 1.62$ \\
\hline 10 Durango & 0,24 & 0,2 & 0,11 \\
\hline 11 Guanajuato & 0,73 & 0,89 & 0,64 \\
\hline 12 Guerrero & 0,84 & 0,95 & $n / a^{1}$ \\
\hline 13 Hidalgo & 0,59 & 0,76 & 0,46 \\
\hline 14 Jalisco & 0,54 & 0,34 & 0,37 \\
\hline 15 México & 0,55 & 0,5 & 0,15 \\
\hline 16 Michoacán de O. & 0,04 & 0,24 & 0,08 \\
\hline 17 Morelos & 0,59 & $* * 2.53$ & 0,33 \\
\hline 18 Nayarit & $* * 2.80$ & $* * * 8.33$ & $n / a^{1}$ \\
\hline 19 Nuevo León & 0,96 & $* 1.63$ & $* * * 3.53$ \\
\hline 20 Oaxaca & $* 1.49$ & $* 1.09$ & 0,76 \\
\hline 21 Puebla & $* * 2.01$ & $* * * 3.18$ & $* 1.11$ \\
\hline 22 Querétaro & 0,15 & 0,15 & 0,79 \\
\hline 23 Quintana Roo & $* * * 13.56$ & $* * 2.37$ & $* * * 3.52$ \\
\hline
\end{tabular}




\begin{tabular}{|l|c|c|c|}
\hline Regiones & Qij 2014 & Qij 2009 & Qij 2004 \\
\hline 24 San Luis Potosí & 0,26 & 0,46 & 0,75 \\
\hline 25 Sinaloa & 0,09 & 0,22 & $n / a^{1}$ \\
\hline 26 Sonora & 0,67 & 1,57 & ${ }^{* * 2.07}$ \\
\hline 27 Tabasco & 0,05 & $n / a^{1}$ & $n / a^{1}$ \\
\hline 28 Tamaulipas & $n / a^{1}$ & 0,06 & $n / a^{1}$ \\
\hline 29 Tlaxcala & $* * * 4.51$ & $n / a^{1}$ & $n / a^{1}$ \\
\hline 30 Veracruz de I. & 0,93 & 0,89 & 0,85 \\
\hline 31 Yucatán & $* 1.28$ & $* 1.14$ & $n / a^{1}$ \\
\hline 32 Zacatecas & $* 1.50$ & 0,38 & $* 1.12$ \\
\hline
\end{tabular}

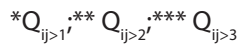

'Los datos por región no han sido recopilados hasta 2013.

Fuente: Elaboración propia (2019).

\section{Variables censales analizadas}

La variable empleo se construyó con la información de la variable censal personal ocupado total; la variable salario se obtuvo dividiendo el total de remuneraciones del censo entre personal ocupado total. La cifra expresa el salario anual en millones de pesos. La variable empresa se retoma de las unidades económicas por regiones en los tres años censales y están expresadas en unidades. En la tabla 4 se observan los resultados de las tres variables por región bajo la clasificación 7121 del SCIAN en los años censales 2004, 2009 y 2013.

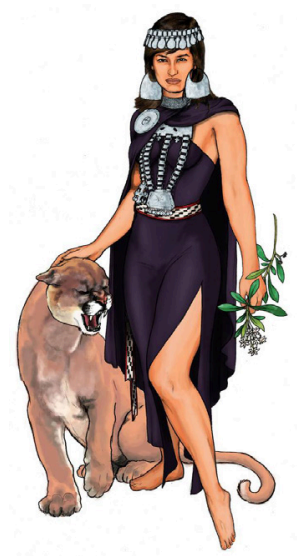




\begin{tabular}{|c|c|c|c|c|c|c|c|c|c|c|c|c|c|c|c|c|c|}
\hline ڤั & $m$ & in & ¿̊ & ¿a & 0 & $\begin{array}{l}0 \\
\vdots\end{array}$ & 0 & $\nabla$ & $\grave{N}$ & $m$ & $=$ & స̃ & $m$ & $\because$ & $\simeq$ & $m$ & 0 \\
\hline 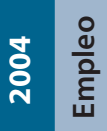 & กิ & $\stackrel{\infty}{\infty}$ & ¿a & ¿a & $\underset{O}{ }$ & ¿a & $m$ & $\stackrel{\unlhd}{\sim}$ & $\stackrel{\infty}{\infty}$ & $\nabla$ & হ & sa & $\stackrel{a}{-}$ & $\curvearrowright$ & ๓े & 0 & $\underline{m}$ \\
\hline$\frac{\stackrel{n}{\frac{0}{n}}}{\frac{\pi}{\pi}}$ & 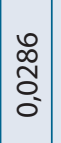 & $\begin{array}{l}\stackrel{\varpi}{\infty} \\
\bar{\sigma} \\
\vdots\end{array}$ & ปี & $\begin{array}{l}\text { こ̃ } \\
\text { ב }\end{array}$ & $\begin{array}{l}\hat{\infty} \\
o \\
0 \\
0\end{array}$ & こ̃ & 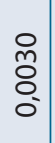 & $\begin{array}{l}\pi \\
\delta \\
\delta \\
0\end{array}$ & 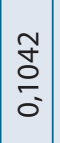 & \begin{tabular}{l}
$\infty$ \\
\multirow{2}{0}{} \\
0 \\
0 \\
0
\end{tabular} & $\begin{array}{l}\hat{N} \\
\tilde{m} \\
0 \\
0\end{array}$ & 气̃ & $\begin{array}{l}\bar{\infty} \\
0 \\
0 \\
0\end{array}$ & $\begin{array}{l}n \\
\infty \\
0 \\
0 \\
0\end{array}$ & $\begin{array}{l}\stackrel{0}{1} \\
\frac{0}{0} \\
0\end{array}$ & $\begin{array}{l}\circ \\
\stackrel{0}{0} \\
0 \\
0\end{array}$ & $\begin{array}{l}\infty \\
0 \\
0 \\
0 \\
0 \\
0\end{array}$ \\
\hline 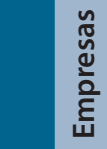 & a & $\stackrel{\circ}{-}$ & a & $\stackrel{0}{\varrho}$ & $\simeq$ & $\begin{array}{l}1 \\
\vdots \\
1\end{array}$ & $=$ & $\stackrel{\Perp}{\leftarrow}$ & $\stackrel{\infty}{m}$ & $\nabla$ & ○ & $\infty$ & 0 & $\stackrel{\eta}{\sim}$ & $\approx$ & $\underline{m}$ & ก \\
\hline 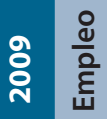 & ja & $\stackrel{\nabla}{\sim}$ & $\bar{\Xi}$ & ¿a & $\hat{m}$ & ¿a & o & ถู & ‡ & $ㅇ$ & 음 & $\stackrel{\infty}{\infty}$ & $n$ & ○ & ষ্ণ & $\bar{m}$ & $\stackrel{n}{0}$ \\
\hline$\frac{\stackrel{n}{\frac{0}{n}}}{\frac{\pi}{n}}$ & $\begin{array}{l}\hat{f} \\
\text { 足 } \\
0\end{array}$ & 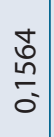 & 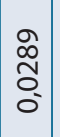 & $\stackrel{\Xi}{\Xi}$ & 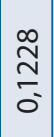 & $\begin{array}{l}\tilde{z} \\
\Sigma\end{array}$ & $\begin{array}{l}\frac{J}{2} \\
0 \\
0\end{array}$ & $\begin{array}{l}n \\
0 \\
0 \\
0 \\
0\end{array}$ & 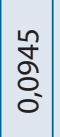 & $\begin{array}{l}8 \\
8 \\
0 \\
0\end{array}$ & $\begin{array}{l}0 \\
\frac{0}{2} \\
0 \\
0\end{array}$ & $\frac{a}{\delta}$ & 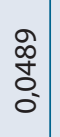 & $\begin{array}{l}0 \\
0 \\
0 \\
0 \\
0\end{array}$ & $\begin{array}{c}0 \\
m \\
\vdots \\
0 \\
0\end{array}$ & $\begin{array}{l}\text { No } \\
\text { ¿ }\end{array}$ & స్ \\
\hline 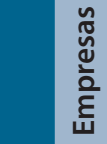 & $m$ & $\bar{\sim}$ & $\underline{m}$ & ¿a & $\infty$ & $\mid \begin{array}{l}1 \\
1 \\
1\end{array}$ & \pm & 으 & f & $\infty$ & $\bar{m}$ & $=$ & $\wedge$ & $\overline{\text { in }}$ & $\stackrel{\infty}{\sim}$ & in & $\simeq$ \\
\hline 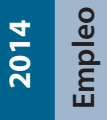 & $\approx$ & 官 & $\underset{ป}{~}$ & $\stackrel{0}{2}$ & $\stackrel{ }{\underline{m}}$ & పे & in & ○ & $\begin{array}{l}\hat{\infty} \\
\infty \\
\infty\end{array}$ & $\bar{\sim}$ & $\stackrel{\stackrel{n}{\Lambda}}{\sim}$ & $\stackrel{\infty}{\circ}$ & $\mathscr{0}$ & $\stackrel{\circ}{\stackrel{0}{N}}$ & ర্ & $\wedge$ & in \\
\hline$\frac{\stackrel{0}{\frac{0}{n}}}{\frac{\pi}{n}}$ & $\begin{array}{l}8 \\
8 \\
\delta\end{array}$ & $\frac{\bar{n}}{\underset{0}{\tilde{D}}}$ & $\stackrel{\tilde{c}}{\check{c}}$ & 气ే & 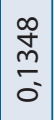 & $\begin{array}{l}\tilde{c} \\
\check{c}\end{array}$ & $\begin{array}{l}\text { ำ } \\
8 \\
0 \\
0\end{array}$ & $\begin{array}{l}\tilde{N} \\
\hat{\delta} \\
0\end{array}$ & $\frac{0}{\mathfrak{d}}$ & $\begin{array}{l}\infty \\
\omega_{n}^{\infty} \\
\hat{0} \\
0 \\
0\end{array}$ & $\begin{array}{l}m \\
\infty \\
\omega \\
0 \\
0 \\
0\end{array}$ & $\begin{array}{l}0 \\
\frac{8}{8} \\
0\end{array}$ & $\begin{array}{l}\stackrel{N}{N} \\
\tilde{\sigma} \\
0\end{array}$ & $\begin{array}{l}0 \\
\text { Ln } \\
0 \\
0 \\
0\end{array}$ & $\begin{array}{l}\infty \\
\stackrel{\infty}{n} \\
\vdots \\
0 \\
0\end{array}$ & ষ & 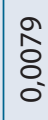 \\
\hline 흠 & 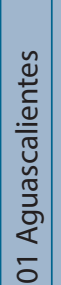 & 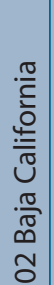 & 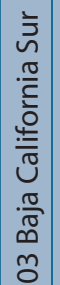 & 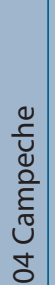 & 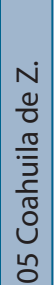 & 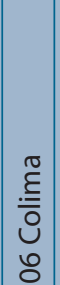 & $\begin{array}{l}\tilde{n} \\
0 \\
\frac{0}{0} \\
\frac{0}{\tilde{U}} \\
\hat{0}\end{array}$ & 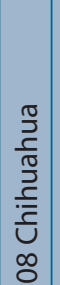 & 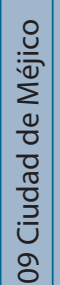 & 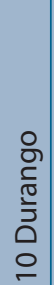 & $\begin{array}{l}0 \\
\stackrel{0}{0} \\
\stackrel{T}{0} \\
\frac{0}{c} \\
\frac{0}{0} \\
0 \\
= \\
=\end{array}$ & 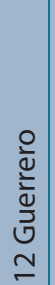 & $\begin{array}{l}\frac{0}{\frac{0}{n}} \\
\frac{0}{0} \\
\frac{0}{1} \\
m\end{array}$ & 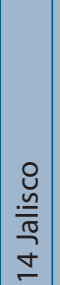 & $\sum_{\substack{0 \\
\hdashline}}^{\stackrel{0}{\sigma}}$ & 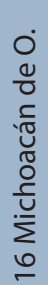 & 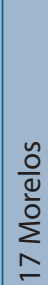 \\
\hline
\end{tabular}




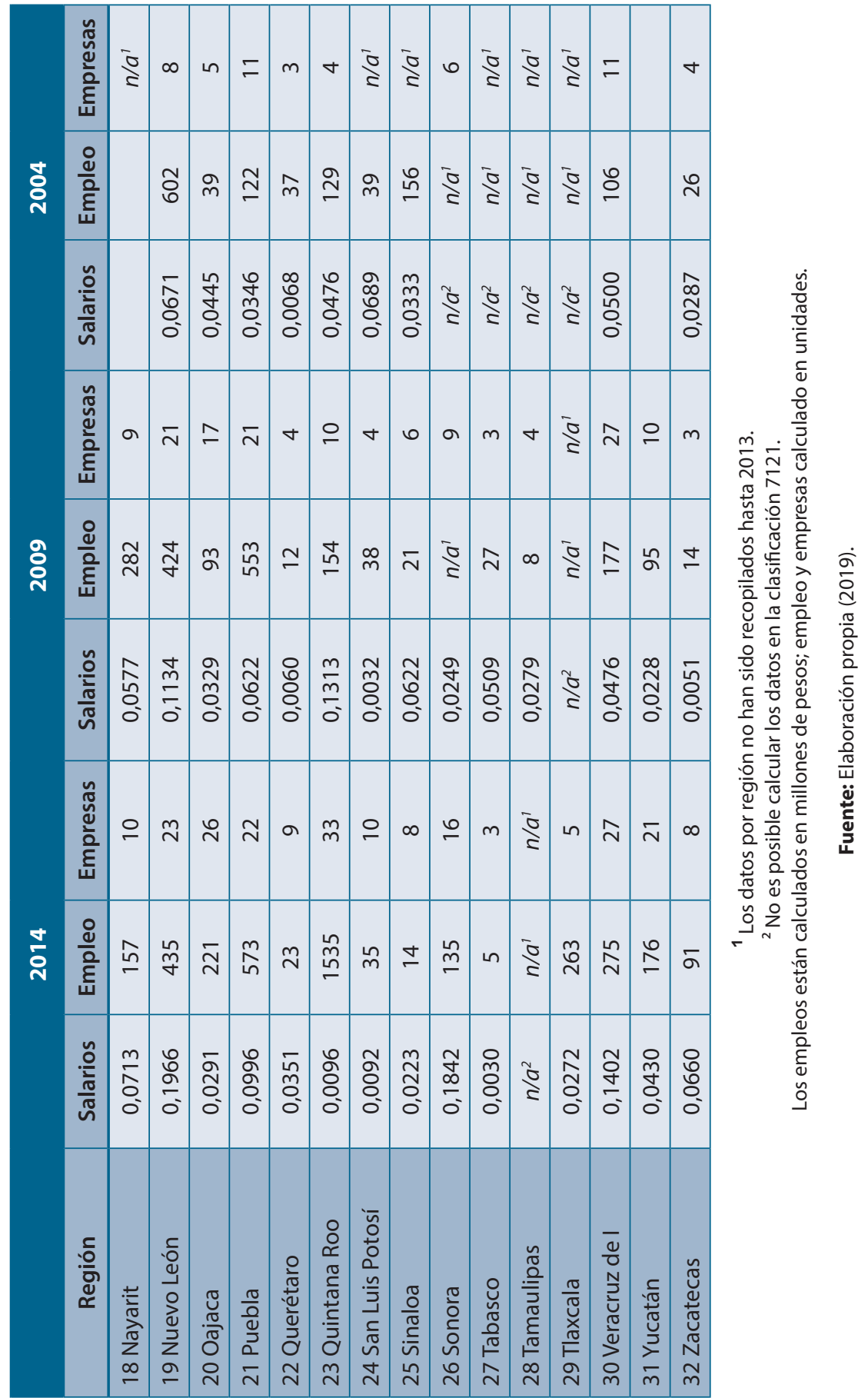


En los tres años censales se realizó correlación de $r^{2}$ Pearson entre el coeficiente de localización $Q_{i j}$ como variable exógena, y los valores de salarios, empresas y empleo como variables endógenas. Cabe señalar que existen datos por región que no han sido recopilados hasta 2013 por los censos económicos en Méjico para la clasificación 7121 del SCIAN; de igual manera, no fue posible calcular algunos datos en las regiones como se observa en la tabla 4, por lo que se realizó la correlación sobre las regiones cuyos datos hayan sido recopilados en los tres años censales. Los resultados de las variables analizadas se muestran en la tabla 5.

Tabla 5. Correlación $r^{2}$ entre variables obtenidas del 7121 del SAIC de Méjico

\begin{tabular}{c|c|c|c|}
\hline Año censal & Qij/Salarios & Qij/empleo & Qij/Empresa \\
\hline 2014 & $-0,11$ & ${ }^{*} 0.79$ & 0,26 \\
\hline 2009 & 0,27 & 0,35 & 0,10 \\
\hline 2004 & 0,46 & ${ }^{*} 0.57$ & 0,09 \\
\hline
\end{tabular}
${ }^{*} r^{2}>5.0$
$Q_{i j}$ Variable exógena.
Salarios, empresa, empleo son variables endógenas.

Fuente: Elaboración propia (2019).

En Méjico, entre siete y ocho regiones tienen un coeficiente de localización mayor a una unidad $\left(Q_{i j>1}\right)$ en los tres años censales de las 32 regiones. En la tabla 3 se identifican cinco regiones altamente especializadas $\left({ }^{* * *} Q_{i j>3}\right)$ en comparación con los otros 27 estados de Méjico: Quintana Roo, Baja California Sur, Tlaxcala, Nayarit y Puebla. Estas regiones se encuentran en la costa del país (ver figura 1), lo que deduce una polarización de habilidades especializadas en el turismo de naturaleza y cultura por regiones, donde se conglomeran en las costas mejicanas como parte del encadenamiento a destinos consolidados de sol y playa como son: Quintana Roo con Playa del Carmen y Cancún; Nayarit con Riviera Nayarit, y Baja California Sur con Cabo San Lucas.

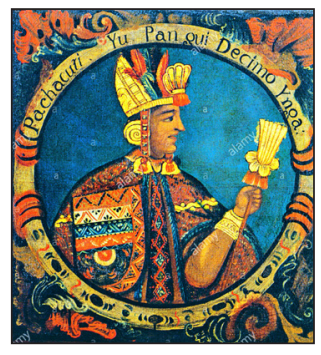


Figura 1. del ecoturismo y turismo cultura en Méjico en el censo de 2014

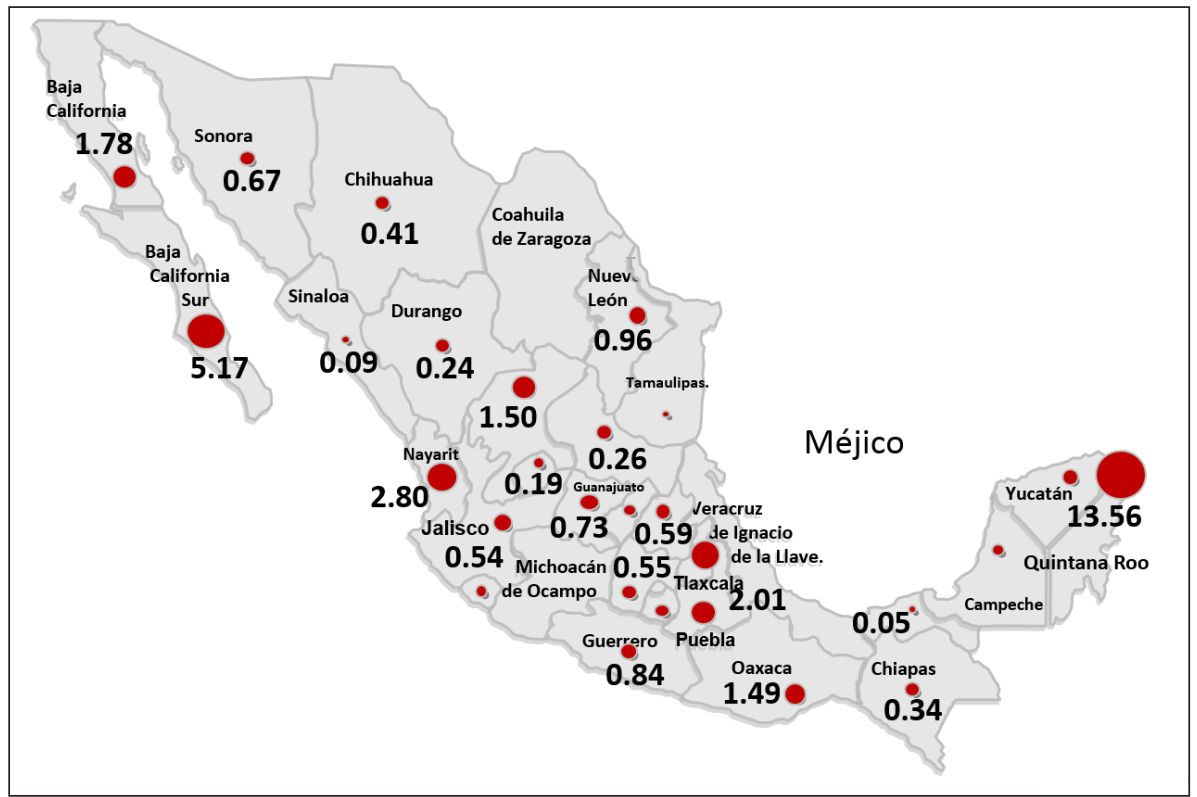

Fuente: Elaboración propia (2020).

Los Estados de Puebla y Tlaxcala, del centro del país, tienen un alto coeficiente de localización. Ambas regiones participan en los programas Pueblos Mágicos y Ruta de los Dioses. El programa Pueblos Mágicos es destinado a ciudades que están ubicados en zonas cercanas a sitios turísticos o grandes ciudades y que tienen algún valor o motivo histórico o religioso.

En la tabla 6 se identifican 9 pueblos mágicos en el Estado de Puebla ubicándolo como la región con mayor número de pueblos mágicos en el país junto con el Estado de Méjico. Por su parte, Tlaxcala, localizado en el centro de país y vecino de Puebla, es poseedor de un conocido centro colonial y dos pueblos mágicos. Tlaxcala presenta un coeficiente de correlación muy elevado (4.51) en el año censal 2014 (no se tiene información de los años censales anteriores). De lo anterior, se infiere que Tlaxcala ha sido un Estado turístico especializado por su patrimonio cultural en años previos.

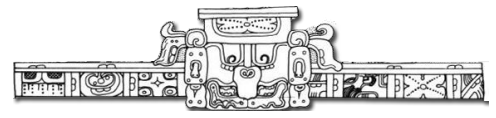


Tabla 6. Pueblos Mágicos de Méjico

\begin{tabular}{|c|c|c|c|c|c|c|c|}
\hline $\mathbf{N}^{\circ}$ & Estado & Pueblo Mágico & Año & $\mathbf{N}^{\circ}$ & Estado & Pueblo Mágico & Año \\
\hline \multirow{3}{*}{1} & \multirow{3}{*}{ Aguascalientes } & Real de Asientos & 2006 & \multirow{2}{*}{16} & \multirow{2}{*}{ Morelos } & Tepoztlan & 2010 \\
\hline & & Calvillo & 2012 & & & Tlayacapan & 2011 \\
\hline & & San José de Gracia & 2015 & \multirow[b]{2}{*}{17} & \multirow[b]{2}{*}{ Nayarit } & Jala & 2012 \\
\hline 2 & Baja California & Tecate & 2012 & & & Sayulita & 2015 \\
\hline \multirow[t]{2}{*}{3} & $\begin{array}{c}\text { Baja California } \\
\text { Sur }\end{array}$ & Todos Santos & 2006 & \multirow{2}{*}{18} & \multirow{2}{*}{$\begin{array}{l}\text { Nuevo } \\
\text { León }\end{array}$} & Santiago & 2006 \\
\hline & Campeche & $\begin{array}{l}\text { Loreto } \\
\text { Palizada }\end{array}$ & \begin{tabular}{|l|}
2012 \\
2010
\end{tabular} & & & Linares & 2015 \\
\hline \multirow{4}{*}{5} & \multirow{4}{*}{ Chiapas } & San Cristobal de las Casas & 2003 & \multirow{5}{*}{19} & \multirow{5}{*}{ Oaxaca } & Capulálpam de Méndez & 2007 \\
\hline & & Comitán de Domínguez & 2012 & & & Huautla de Jiménez & 2015 \\
\hline & & Chiapa de Corzo & 2012 & & & Mazunte & 2015 \\
\hline & & Palenque & 2015 & & & San Pablo Villa de Mitla & 2015 \\
\hline \multirow{3}{*}{6} & \multirow{3}{*}{ Chihuahua } & Creel & 2007 & & & San Pedro y San Pablo & 2015 \\
\hline & & Batopilas & 2012 & \multirow{9}{*}{20} & \multirow{9}{*}{ Puebla } & Cuetzalan & 2002 \\
\hline & & Casas Grandes & 2015 & & & Zacatlán de las Manzanas & 2011 \\
\hline \multirow{6}{*}{7} & \multirow{6}{*}{ Coahuila } & Parras de la Fuente & 2004 & & & Pahuatlán & 2012 \\
\hline & & Cuatro Ciénegas & 2012 & & & Chignahuapan & 2012 \\
\hline & & Arteaga & 2012 & & & Cholula & 2012 \\
\hline & & Viesca & 2012 & & & Tlatlauquitepec & 2012 \\
\hline & & Candela & 2015 & & & Xicotepec & 2012 \\
\hline & & Guerrero & 2015 & & & Atlixco & 2015 \\
\hline 8 & Colima & Comala & 2002 & & & Huauchinango & 2015 \\
\hline 9 & Durango & Mapimí & 2012 & \multirow{5}{*}{21} & \multirow{5}{*}{ Querétaro } & Bernal & 2005 \\
\hline \multirow{6}{*}{10} & \multirow{5}{*}{ Guanajuato } & Dolores Hidalgo & 2002 & & & Jalpan de Serra & 2010 \\
\hline & & Mineral del Pozo & 2012 & & & Cadereyta & 2011 \\
\hline & & Jalpa & 2012 & & & Tequisquiapan & 2012 \\
\hline & & Salvatierra & 2012 & & & San Joaquín & 2015 \\
\hline & & 年 & 2012 & & & Bacalar & 2006 \\
\hline & Guerrero & Taxco & 2002 & 22 & $\begin{array}{l}\text { Quintana } \\
\text { Roo }\end{array}$ & Isla Mujeres & 2015 \\
\hline & & Huasca de Ocampo & 2001 & & & Tulum & 2015 \\
\hline & & Real del Monte & 2004 & 23 & San Luis & Real de Catorce & 2001 \\
\hline 12 & Hidalgo & Mineral el chico & 2011 & & Potosí & Xilitla & 2011 \\
\hline & & Huichapan & 2012 & & & Cosalá & 2005 \\
\hline & & Tecozautla & 2015 & 24 & Sinaloa & El Fuerte & 2009 \\
\hline & & Tapalpa & 2002 & & & El Rosarito & 2012 \\
\hline & & Tequila & 2003 & & & Mocorito & 2015 \\
\hline & & Mazamitla & 2005 & 25 & Sonora & Álamos & 2005 \\
\hline 13 & Jalisco & San Sebastián del Oeste & 2011 & 20 & 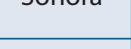 & Magdalena de Kino & 2012 \\
\hline & & Lagos de Moreno & 2012 & 26 & Tabasco & Tapijulapa & 2010 \\
\hline & & Mascota & 2015 & 27 & Tamaulipas & Mier & 2007 \\
\hline & & Talpa de Allende & 2015 & 4 & ramianimas & Tula & 2011 \\
\hline
\end{tabular}




\begin{tabular}{|c|c|c|c|c|c|c|c|}
\hline $\mathbf{N}^{\circ}$ & Estado & Pueblo Mágico & Año & $\mathbf{N}^{\circ}$ & Estado & Pueblo Mágico & Año \\
\hline \multirow{9}{*}{14} & \multirow{9}{*}{$\begin{array}{c}\text { Estado de } \\
\text { Méjico }\end{array}$} & Tepotzotlán & 2002 & \multirow{2}{*}{28} & \multirow{2}{*}{ Tlaxcala } & Huamantla & 2007 \\
\hline & & Valle de Bravo & 2005 & & & Tlaxco & 2015 \\
\hline & & Malinalco & 2010 & \multirow{7}{*}{29} & \multirow{7}{*}{ Veracruz } & Xico & 2001 \\
\hline & & El Oro & 2011 & & & Coatepec & 2006 \\
\hline & & Metepec & 2012 & & & & \\
\hline & & Aculco & 2015 & & & Papantla & 2012 \\
\hline & & $\begin{array}{l}\text { Teotihuacán y S. Martín } \\
\text { Pirámides }\end{array}$ & 2015 & & & Coscomatepec & 2015 \\
\hline & & Ixtapan de la Sal & 2015 & & & Orizaba & 2015 \\
\hline & & Villa del Carbón & 2015 & & & Zozocolco & 2015 \\
\hline \multirow{8}{*}{15} & \multirow{8}{*}{ Michoacán } & Pátzcuaro & 2002 & \multirow{2}{*}{30} & \multirow{2}{*}{ Yucatán } & Izamal & 2002 \\
\hline & & Tlalpujahua & 2005 & & & Valladolid & 2015 \\
\hline & & Cuitzeo & 2006 & \multirow{6}{*}{31} & \multirow{6}{*}{ Zacatecas } & Jerez de García Salinas & 2007 \\
\hline & & Santa Clara del Cobre & 2010 & & & Teul González Ortega & 2011 \\
\hline & & Angangueo & 2012 & & & & \\
\hline & & Tacámbaro & 2012 & & & Sombrerete & 2012 \\
\hline & & Jiquilpan & 2012 & & & Pinos & 2012 \\
\hline & & Tzintzuntzan & 2012 & & & Nochistlán & 2012 \\
\hline
\end{tabular}

Fuente: Elaboración propia con base en la Sectur (2019).

Las 6 regiones que en los censos 2004 o 2009 contaban con un coeficiente de localización mayor a uno y para el 2014 su coeficiente de localización fue menor a una unidad fueron: Aguas Calientes, Coahuila de Z., Ciudad de Méjico, Morelos, Nuevo León y Sonora. En la figura 1 se ubican en el centro y norte del país. Lo anterior puede referir que los Estados iniciaron un proceso de diversificación sectorial en su producto turístico. La teoría indica que aquellas regiones con una gran economía metrópoli tienen motivos para diversificarse, ya que las economías de urbanización proporcionan insumos generales a escalas eficientes que son útiles para muchas actividades en una región, tal es el caso de Ciudad de Méjico y Nuevo León que son grandes metrópolis con un gran aporte al PIB.

Un alto coeficiente de localización no indica que será bueno o malo para los ingresos regionales en la economía mejicana en cuanto al ecoturismo y turismo cultural. En relación con los salarios, los indicadores en el año censal 2014 para las regiones con un alto coeficiente de localización, Quintana Roo y Baja California Sur, se identifica que han disminuido notablemente su indicador salarial (ver tabla 3). Baja California Sur de 0.15 millones de pesos en 2009 disminuye a 0.12 millones de pesos en 2014; Quintana Roo pasó de 0.1313 millones de pesos en 2009 a 0.0096 millones de pesos en 2014. 
Por su parte, Puebla obtuvo un incremento en sus salarios considerable en los tres años censales, pasó de 0.034 millones de pesos a 0.062 millones en 2009, posteriormente, en 2014 se ubicó con 0.099 millones. Lo anterior indicaría que, de acuerdo con las teorías de conglomeración, sus salarios son una medida de su alta representatividad productiva en el turismo cultural al requerir mano de obra especializada en tecnología y procesos.

Los salarios en el año censal 2014 en el ecoturismo y turismo cultural tienen una asociación con mayor relevancia por la ubicación geográfica de la región. En la figura 2 se observa que las regiones que están en frontera con Estados Unidos tienen los mejores salarios (excepto el Estado de Coahuila de Z.) Así mismo, se observa que en el sureste del país tienen los menores salarios (con excepción de Yucatán). Lo anterior es relevante porque en los estados del sureste se encuentran los destinos de turismo de naturaleza y cultura con gran relevancia para el país. En esta zona geográfica el programa Mundo Maya pretendió impulsar el fortalecimiento de la región, a través del desarrollo de nuevos productos y de la consolidación de la oferta existente en el marco del desarrollo turístico sustentable con la participación de los sectores público y privado e incorporando a las comunidades locales.

Figura 2. Salarios del ecoturismo de naturaleza en Méjico - 2014

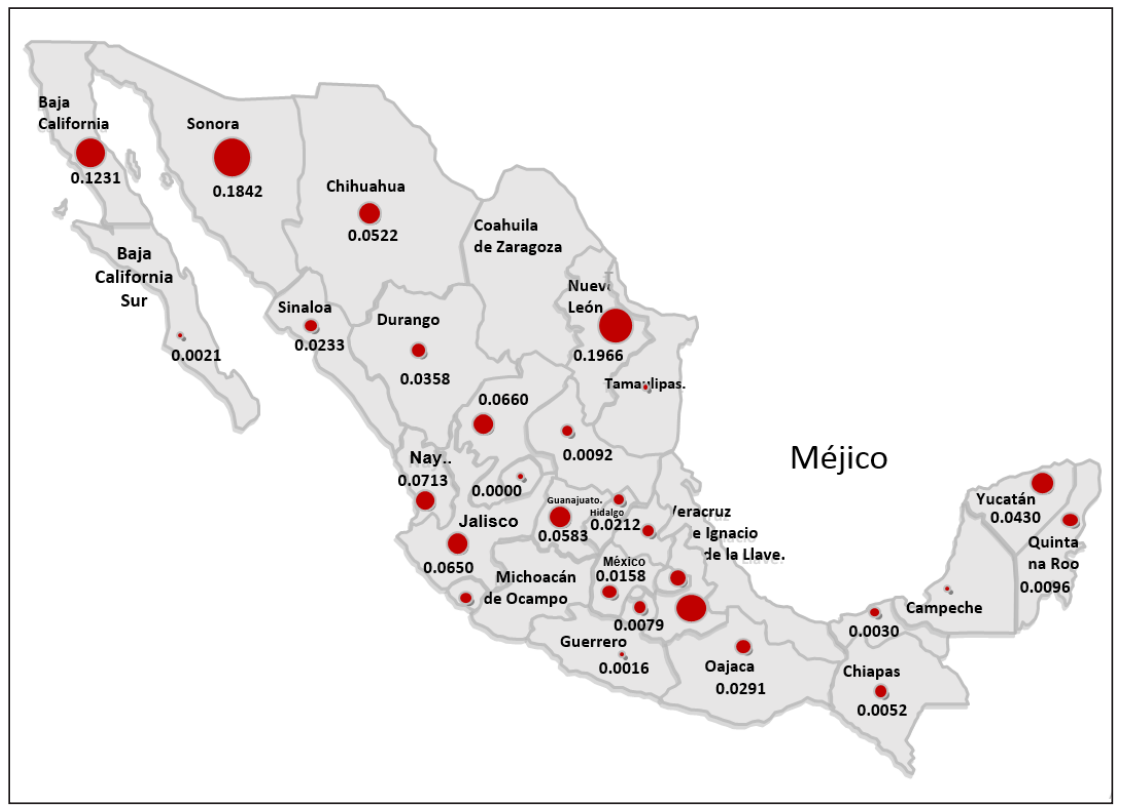

Fuente: Elaboración propia (2019). 


\section{Desarrollo sostenible en el ecoturismo y turismo cultural en Méjico: sostenibilidad ecoturística}

Para lograr la sostenibilidad en los destinos turísticos se debe inducir la práctica y operatividad del marco institucional y legal, así como los principios de planificación y gestión del destino (Vera citado por CamachoRui et al., 2016:158). Sin embargo, el compromiso de sostenibilidad a través de los sistemas de acreditación presenta un producto turístico basado en una selección de los mejores espacios protegidos y de las empresas de turismo mejor preparadas, para lo cual en Méjico se han articulado una serie de mecanismos de acreditación que comprueban la existencia y valoración de una especialización del turismo de naturaleza, ya no solo de las empresas que realizan las actividades, sino también de los espacios donde se desarrollan (Guillén, 2017).

La norma mejicana NMX-AA-133-SCFI-2013 contiene los requisitos y especificaciones de sostenibilidad del ecoturismo en tres dimensiones: ambiente, sociocultural y economía. Su objetivo es establecer los requisitos, especificaciones de desempeño ambiental en el ecoturismo y el procedimiento de evaluación de la conformidad para efectos de certificación. Los requisitos y especificaciones de la norma buscan orientar la asignación y ejecución de apoyos públicos y privados en materia de ecoturismo (Secretaría de Economía, 2014:3).

La norma NMX-AA-133-SCFI-2013 es de cumplimiento voluntario y aplica a personas físicas o morales e interesados en el desempeño sustentable y buenas prácticas ambientales en el ecoturismo en Méjico. La norma está conformado por requisitos generales del documento de planeación del producto ecoturístico; requisitos para la ubicación de instalaciones, diseño y construcción; requisitos para actividades de interpretación ambiental y procedimientos de evaluación de conformidad de certificación acreditado por la Secretaría de Medio Ambiente y Recursos Naturales (Semarnat) o la Procuraduría Federal de Protección al Ambiente (Profepa) (Secretaría de Economía, 2014:4). La norma incluye un apéndice normativo sobre su metodología de evaluación en el que se numera cada requisito con su medio de verificación y los criterios de valoración. Conforme al cumplimiento y entrega de los productos finales se obtiene una ponderación (Camacho et al., 2016:161).

\section{Empresas certificadas}

En Méjico hay 25 centros ecoturísticos que han implementado la Norma Mejicana NMX-AA-133-SCFI-2013 de carácter voluntario. Las empresas 


\section{4}

se ubican en los estados Yucatán, Quintana Roo, Chiapas, Estado de Méjico, Puebla, Querétaro y Guanajuato, de las cuales 17 tienen la marca de Paraísos Indígenas de la Comisión Nacional para el Desarrollo de los Pueblos Indígenas (CDI). Con esta entrega, hasta el 2019 hay 35 empresas en 12 estados de Méjico. Como se observa en la figura 3 las empresas se encuentran localizadas en el centro y sureste del país con excepción de Baja California, ubicada en la frontera norte. Las empresas ubicadas en Quintana Roo, Campeche, Oaxaca y Baja California iniciaron sus certificación a principios de 2006 y se han consolidado con la actualización de la norma a lo largo del tiempo, a diferencia de las empresas ubicadas en el centro del país, quienes lograron obtener su certificación en 2019 (Secretaría de Medio Ambiente y Recursos Naturales, 2018:1).

Figura 3. Localización de empresas ecoturísticas certificadas al 2019

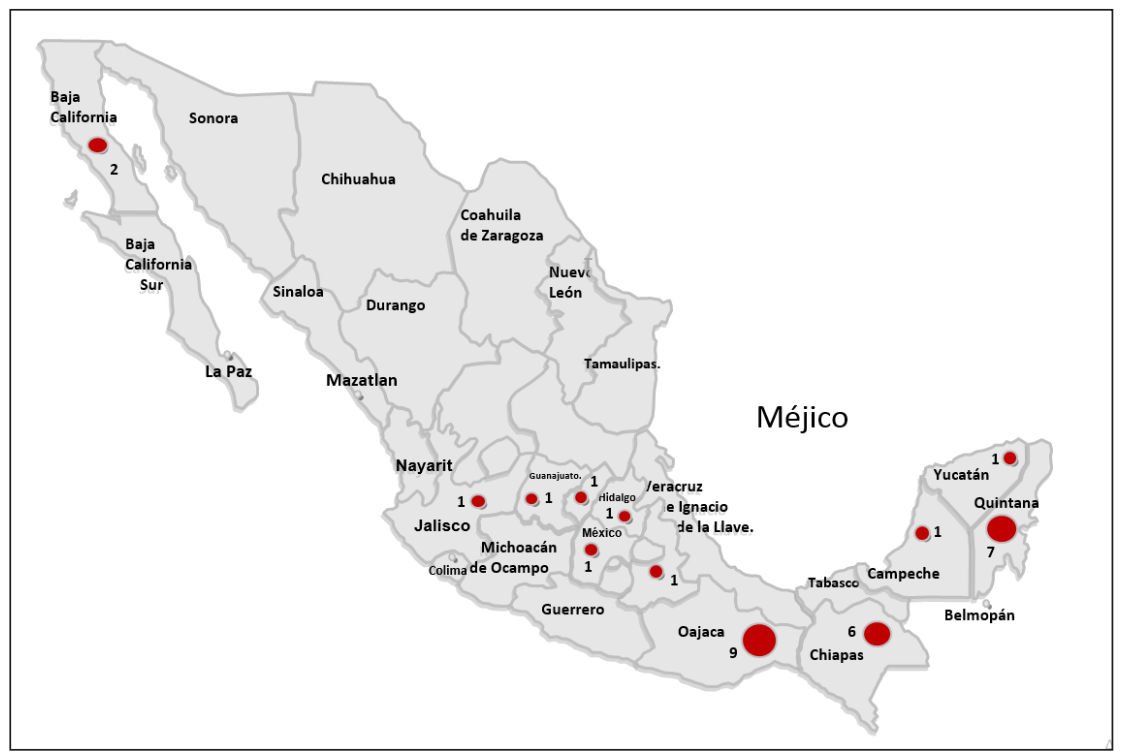

Fuente: Elaboración propia con base en SEMARNAT (2019).

La baja cantidad de unidades económicas certificadas en la Norma NMXAA-133-SCFI-2013 se relaciona con los indicadores del ODS número 7, garantizar la sostenibilidad del medio ambiente en todo el país, donde el Gobierno mejicano incorpora los principios de desarrollo sostenible en las políticas y programas nacionales para intervenir en la pérdida de recursos del medio ambiente. En la figura 4 se observa que hay un estancamiento por parte del Gobierno mejicano en reducir la emisión de dióxido de carbono total y proporción total de recursos hidráulicos utilizados, así mismo, el Gobierno expresa un progreso insuficiente 
en la protección de la superficie cubierta por bosques y selvas. Lo más significativo es que el Gobierno mejicano no tiene datos suficientes de la proporción sostenible de especies en peligro de extinción (Presidencia de la República - Gobierno de Méjico, 2013:29).

Figura 4. Resultados del Objetivo de Desarrollo Sostenible número 7 en Méjico

\begin{tabular}{|c|c|c|c|c|c|c|c|}
\hline Indicador ${ }^{a /}$ & $\begin{array}{l}\text { Línea } \\
\text { base } \\
1990^{b /}\end{array}$ & 2000 & 2005 & 2010 & $\begin{array}{l}\text { Última } \\
\text { fecha } \\
\text { disponible }\end{array}$ & Meta & $\begin{array}{l}\text { ¿Cómo va } \\
\text { Méjico? }\end{array}$ \\
\hline \multicolumn{8}{|c|}{ Objetivo 7. Garantizar la sostenibilidad del medio ambiente } \\
\hline \multicolumn{8}{|c|}{$\begin{array}{l}\text { Meta 7.A. Incorporar los principios del desarrollo sostenible en las políticas y los } \\
\text { programas nacionales e invertir la pérdida de recursos del medio ambiente }\end{array}$} \\
\hline $\begin{array}{l}\text { 7.1. Proporción de la } \\
\text { superficie cubierta } \\
\text { por bosques y selvas }\end{array}$ & $\begin{array}{l}35.3^{\mathrm{p} /} \\
(1993)\end{array}$ & $\begin{array}{c}34.4 \\
(2002)\end{array}$ & $\begin{array}{c}34.0 \\
(2007)\end{array}$ & $\begin{array}{c}33.8 \\
(2011)\end{array}$ & $\begin{array}{c}33.8 \\
(2011)\end{array}$ & Revertir & $\begin{array}{l}\text { Proceso } \\
\text { insuficiente }\end{array}$ \\
\hline $\begin{array}{l}\text { 7.2.a. Emisiones de } \\
\text { dióxido de carbono } \\
\text { per cápita (toneladas } \\
\text { por persona) }\end{array}$ & 4.58 & 4.52 & 4.31 & 4.32 & $\begin{array}{c}4.32 \\
(2010)\end{array}$ & Reducir & $\begin{array}{l}\text { Medida } \\
\text { cumplida }\end{array}$ \\
\hline $\begin{array}{l}\text { 7.2.b. Emisiones de } \\
\text { dióxido de carbono } \\
\text { total (millones de } \\
\text { toneladas) }\end{array}$ & 399.1 & 456.3 & 462.1 & 493.5 & $\begin{array}{l}493.5 \\
(2010)\end{array}$ & Revertir & $\begin{array}{l}\text { Progreso } \\
\text { estancado } \\
\text { o deterioro }\end{array}$ \\
\hline $\begin{array}{l}\text { 7.2.c. Emisiones de } \\
\text { dióxido de carbono } \\
\text { total por PIB por } \\
\text { Paridad de Poder de } \\
\text { Compra (kg. por peso } \\
\text { mexicano) }\end{array}$ & 0.71 & 0.46 & 0.36 & 0.29 & $\begin{array}{c}0.29 \\
(2010)\end{array}$ & Reducir & $\begin{array}{l}\text { Meta } \\
\text { cumplida }\end{array}$ \\
\hline $\begin{array}{l}7.3 \text { Consumo } \\
\text { de sustancias que } \\
\text { agotan la capa de } \\
\text { ozono (kilogramos } \\
\text { ponderados } \\
\text { por habitante) }\end{array}$ & 0.25 & 0.06 & 0.04 & 0.01 & $\begin{array}{c}0.02 \\
(2012)\end{array}$ & Reducir & $\begin{array}{c}\text { Meta } \\
\text { Cumplida }\end{array}$ \\
\hline $\begin{array}{l}\text { 7.5. Proporción del } \\
\text { total de recursos } \\
\text { hídricos utilizada }\end{array}$ & $\begin{array}{c}15.7 \\
(2003)\end{array}$ & ND & 16.2 & 17.4 & $\begin{array}{c}17.4 \\
(2010)\end{array}$ & Revertir & $\begin{array}{c}\text { Proceso } \\
\text { Estancado } \\
\text { o deterioro }\end{array}$ \\
\hline \multicolumn{8}{|c|}{$\begin{array}{l}\text { Meta 7B: Reducir la pérdida de biodiversidad, alcanzando, para el año 2010, una } \\
\text { reducción significativa de la tasa de pérdida }\end{array}$} \\
\hline $\begin{array}{l}\text { 7.6. Proporción } \\
\text { de áreas terrestres } \\
\text { y marinas protegidas }\end{array}$ & 7.1 & 11.2 & 11.8 & 13.0 & $\begin{array}{c}13.0 \\
(2012)\end{array}$ & $\begin{array}{c}\text { Aumen- } \\
\text { tar }\end{array}$ & $\begin{array}{c}\text { Meta } \\
\text { Cumplida }\end{array}$ \\
\hline $\begin{array}{l}\text { 7.7. Proporción } \\
\text { de especies en } \\
\text { peligro de extinción }\end{array}$ & \multicolumn{5}{|c|}{ Ver pag. 155} & Revertir & $\begin{array}{c}\text { Datos } \\
\text { insuficientes }\end{array}$ \\
\hline
\end{tabular}




\begin{tabular}{|c|c|c|c|c|c|c|c|}
\hline Indicador ${ }^{a /}$ & $\begin{array}{l}\text { Línea } \\
\text { base } \\
1990^{b /}\end{array}$ & 2000 & 2005 & 2010 & $\begin{array}{l}\text { Última } \\
\text { fecha } \\
\text { disponible }\end{array}$ & Meta & $\begin{array}{l}\text { ¿Cómo va } \\
\text { Méjico? }\end{array}$ \\
\hline \multicolumn{8}{|c|}{$\begin{array}{l}\text { Meta 7.C. Reducir la mitad, para el año } 2015 \text {, el porcentaje de personas sin acceso } \\
\text { sostenible al agua potable y a servicios básicos de saneamiento }\end{array}$} \\
\hline $\begin{array}{l}\text { 7.8. Proporción } \\
\text { de la población } \\
\text { con acceso sostenible } \\
\text { a fuentes mejoradas } \\
\text { de abastecimiento } \\
\text { de agua, en zonas } \\
\text { urbanas y rurales }\end{array}$ & 78.4 & 87.8 & 89.2 & 90.9 & $\begin{array}{c}90.9 \\
(2010)\end{array}$ & 89.2 & $\begin{array}{l}\text { Meta } \\
\text { Cumplida }\end{array}$ \\
\hline $\begin{array}{l}\text { 7.9. Proporción de } \\
\text { la población con } \\
\text { acceso a servicios } \\
\text { de saneamiento } \\
\text { mejorados, en zonas } \\
\text { urbanas y rurales }^{r /}\end{array}$ & 58.6 & 72.8 & 83.5 & 87.7 & $\begin{array}{c}87.7 \\
(2010)\end{array}$ & 79.3 & $\begin{array}{l}\text { Meta } \\
\text { Cumplida }\end{array}$ \\
\hline \multicolumn{8}{|c|}{$\begin{array}{l}\text { Meta 7.D. Haber mejorado considerablemente, para el año 2020, la vida de por lo } \\
\text { menos } 100 \text { millones de habitantes de tugurios }\end{array}$} \\
\hline $\begin{array}{l}\text { 7.10. Proporción de } \\
\text { la población urbana } \\
\text { que habita en } \\
\text { viviendas precarias }\end{array}$ & $\begin{array}{l}35.68 \\
(1992)\end{array}$ & 23.57 & 14.40 & 15.30 & $\begin{array}{l}17.06 \\
(2012)\end{array}$ & Reducir & $\begin{array}{l}\text { Meta } \\
\text { Cumplida }\end{array}$ \\
\hline
\end{tabular}

Fuente: Gobierno de la República Mejicana (2013).

\section{Conclusiones}

Los escenarios que marca la especialización relativa en el sector turístico de naturaleza, en su modalidad ecoturismo y cultura, es una actividad económica a nivel de país muy poco especializada en los años censales 2004, 2009 y 2014, con bajos salarios y una correlación moderada en la creación de empleo, donde sus salarios tienen una asociación con mayor relevancia por la ubicación geográfica de la región.

Méjico cuenta con un gran patrimonio natural y cultural y suficientes políticas nacionales para consolidar el ecoturismo y turismo cultural con programas como Mundo Maya y Ruta de los Dioses; sin embargo, no se observa un avance significativo de sectores especializados a nivel nacional a través del tiempo. Esta situación no es así en las regiones que están en la costa del país con un producto ecoturístico y cultural encadenado a los destinos consolidados de sol y playa. El único caso de éxito con un incremento de coeficiente de especialización y salarios en los tres años censales es Puebla, es decir, es un Estado especializado en cultura a niveles de exportación del producto. 
En América Latina el término sustentabilidad se emplea como sinónimo de sostenibilidad. El Informe de Brundtland en 1987 estableció que el desarrollo sostenible tiene sentido cuando la humanidad satisface sus necesidades del presente sin comprometer la capacidad de las futuras generaciones para satisfacer las propias. Para el turismo de naturaleza y cultura en Méjico es relevante el concepto porque asume que los factores involucrados en el sistema turístico, como superestructura, demanda, comunidad receptora, atractivos, equipamientos e instalaciones e infraestructura (Molina, 1991), se comprometan a lograr la permanencia de los recursos naturales y culturales de Méjico para las futuras generaciones.

Es importante resaltar que, a pesar del esfuerzo conjunto de las organizaciones internacionales e instituciones gubernamentales para apoyar a países en desarrollo para el cumplimiento de los Objetivos de Desarrollo Sostenible, la aplicación en Méjico de la norma de certificación del desempeño sustentable y las buenas prácticas ambientales en el ecoturismo es mínima. La no obligatoriedad de la Norma NMX-AA-133SCFI-2013 permite que empresas ecoturísticas y de cultura operen sin la verificación del cumplimiento de sostenibilidad, poniendo en riesgo la permanencia de sus recursos ambientales y culturales para futuras generaciones. Lo anterior permite sugerir que para los estados que participan en los programas de fomento ecoturístico y de cultura, y que se han beneficiado con recursos públicos para consolidar y posicionar sus destinos, deberían tener la obligatoriedad del cumplimiento de la norma para garantizar la sostenibilidad de sus recursos ambientales y culturales.

\section{Referencias bibliográficas}

1. ARRIAGA, Rosalía, LEYVA, Elitania y ESTRADA, José Luis (2005). Perfil y estructura industrial de Guanajuato y Querétaro: un análisis de la producción, el empleo y los salarios. Análisis Económico, Vol. 20, № 44. Pp. 135-189. Disponible en Internet: https://www.redalyc.org/pdf/413/41304406.pdf

2. BARRÓN, Karla Susana y ARRIOLA, Ulises. (2015). Especialización y productividad del sector turístico en Méjico. Revista Internacional Administración \& Finanzas, Vol. 8 № 5. Pp. 45-61. Disponible en Internet: http://dspace.uan.mx:8080

3. BOISIER, Sergio. (1980). Técnicas de análisis regional con información limitada. Santiago de Chile: N.U. CEPAL. 170 pp.

4. CAMACHO, Edali, CARRILLO, Arturo, RIOJA, Tamara Mila y ESPINOZA, Eduardo. (2016). Indicadores de sostenibilidad para el ecoturismo en Méjico: estado actual. LiminaR, Vol. 14, № 1. Pp. 156-168. Disponible en Internet: http://www.scielo.org.mx/scielo. php?script $=$ sci_arttext\&pid $=$ S1665-80272016000100011 
5. DÍAZ, Alejandro, SOLANO, Irma y SPEAKMAN, Mark (2017). Turismo y sustentabilidad: una revisión conceptual (pp. 119-143). En: Turismo y sustentabilidad: consecuencias del paradigma clásico y nuevos enfoques de desarrollo. Méjico: Universidad Autónoma de Guerrero: Miguel Ángel Porrúa.

6. ELÍAS, Silvina y TUMA, Carla. (2009). Turismo y teoría de clusters, las potencialidades de la localidad de Monte Hermoso. Aportes y Transferencias, Vol. 13, № 1. Pp. 67-92. Disponible en Internet: http://nulan.mdp.edu.ar/1546/

7. FIGUEROLA, Manuel. (2009). Modelos de análisis y sensibilidad para una visión multidimensional del turismo. Turismo una visión multidimensional. En: V Seminario Internacional de Estudios Turísticos, VII Foro de Investigación Turística y II Seminario Internacional de Investigación en Gastronomía. Méjico, Universidad Autónoma del Estado de Méjico.

8. GUILLÉN, Nicolás. (2017). El turismo de naturaleza y la sostenibilidad ambiental (pp. 145-167). En: Turismo y sustentabilidad consecuencias del paradigma clásico y nuevos enfoques de desarrollo. Méjico: Universidad Autónoma de Guerrero.

9. KEMENY, Thomas \& STORPER, Michael. (2014). Is Specialization Good for Regional Economic Development? Regional Studies Association, Vol. 49, № 6. Pp. 1003-1018. https://doi.org/10.1080/00343404.2014.899691

10. LANZA, Alessandro, TEMPLE, Paul \& URGA, Giovanni (2003). The implications of tourism specialisation in the long run: an econometric analysis for $13 \mathrm{OECD}$ economies. Tourism Management, Vol. 24, № 3. Pp. 315-321. https://doi.org/10.1016/ S0261-5177(02)00065-1

11. LOPEZ,GustavoyPALOMINO, Bertha.(2015).Situacióngeneral delas empresas indígenas de turismodenaturalezaenMéjico.RevistaCientíficaTeorías,EnfoquesyAplicacionesenlasCiencias Sociales, Vol. 7, № 16. Pp. 93-106. Disponible en Internet: http://ru.iiec.unam.mx/4500/ MANRIQUE, Olga Lucía. (2006). Fuentes de las economías de aglomeración: una revisión bibliográfica. Cuadernos de Economía, Vol. 25, № 45. Pp. 75-93. Disponible en Internet: https://revistas.unal.edu.co/index.php/ceconomia/article/view/548

12. MÉJICO. Gobierno de la República. (2018). Informe de los Objetivos de Desarrollo Sostenible 2018. Declaración de la Agenda 2030. Disponible en Internet: http:// agenda2030.mx/\#/home Consultado: 17.05.2019.

13. MÉJICO. Instituto Nacional de Estadística y Geografía. INEGI. (2013). Sistema de cuentas nacionales de Méjico. Cuenta satélite del turismo de Méjico, fuentes y metodologías. Disponible en Internet: www.datatur.sectur.gob.mx Consultado: 02.09.2018.

14. MÉJICO. Instituto Nacional de Estadística y Geografía. INEGI. (2018a). Sistema Automatizado de Información Censal. Censos Económicos 2004, 2009 y 2014 de la industria 7121. Disponible en Internet: https://www.inegi.org.mx/app/saic/ Consultado: 13.07.2018.

15. MÉJICO. Instituto Nacional de Estadística y Geografía. INEGI. (2018b). Sistema de Cuentas Nacionales de Méjico. Cuenta satélite del turismo de Méjico 2016 Año base 2013. Disponible en Internet: http://www.datatur.sectur.gob.mx Consultado: 02.09.2018.

16. MÉJICO. Presidencia de la República. (2013). Los Objetivos de Desarrollo del Milenio en Méjico. Informe de Avances. Disponible en Internet: http://biblioteca.semarnat.gob. mx/janium/Documentos/Ciga/Libros2013/CD002128.pdf Consultado: 17.06.2019. 
17. MÉJICO. Secretaría de Economía. (2014). Norma NMX-AA-133-SCFI-2013. Disponible en Internet: http://biblioteca.semarnat.gob.mx/janium/Documentos/Ciga/agenda/ DOFsr/DO3156.pdf Consultado: 19.06.2019.

18. MÉJICO. Secretaría de Medio Ambiente y Recursos Naturales - Semarnat. (2018). Certificados, 35 centros ecoturísticos por mejores prácticas ambientales. Disponible en Internet: https://www.gob.mx/semarnat/prensa/certificados-35-centros-ecoturisticos-por-mejores-practicas-ambientales Consultado: 19.062019.

19. MÉJICO. Secretaría de Turismo (2014). Programas Regionales. Términos regionales, estatales y municipales en los programas regionales. Disponible en Internet: http://www. sectur.gob.mx/programas/programas-regionales/Consultado: 25.08.2018.

20. MÉJICO. Secretaría de Turismo (2015) Portal del sistema nacional de información estadística y geografía de turismo - SNIEGT. Módulo de información de Pueblos Mágicos. Lista de Pueblos Mágicos. Disponible en Internet: https://www.datatur.sectur.gob.mx/Pueblos\%20Magicos/PueblosMagicosIni.aspx Consultado: 20.11.2018.

21. MÉJICO. Secretaría de Turismo (2016) Análisis Integral del Turismo - Datatur. Resultados de la Actividad Turística. Disponible en Internet: http://www.datatur.sectur.gob.mx Consultado: 16.08.2018.

22. MÉJICO. Secretaría de Turismo (2017a). Estrategia para el Impulso y Desarrollo del Turismo de Naturaleza en Méjico. Subsecretaría de planeación y política turística de la Dirección de Política Intersectorial. Disponible en Internet: file:///Users/marisolavila/ Documents/Revista\%20Teuken\%20Bidikay/ETNM_v3_oct17.pdf Consultado: 18.08.2018.

23. MÉJICO. Secretaría de Turismo. (2017b). Estudio de la Política Turística de Méjico Resumen Ejecutivo, Evaluación y Recomendaciones. Disponible en Internet: https:// www.datatur.sectur.gob.mx/ Consultado: 9.12.2017.

24. MÉJICO. Sistema de Clasificación Industrial de América del Norte (2018). Metadato: Servicios de esparcimiento culturales y deportivos, y otros servicios recreativos. Disponible en Internet: https://www.inegi.org.mx/app/scian/ Consultado: 9.12.2018.

25. MÉJICO. Sistema de Cuentas Nacionales de Méjico (2018). Cuenta satélite del turismo de Méjico 2016, año base 2013. Instituto Nacional de Estadística y Geografía. Pp. 3-8. Disponible en Internet: https://www.datatur.sectur.gob.mx/Documentos $\% 20$ compartidos/CSTM_Ed_2018.pdf Consultado: 10.12.2018.

26. MONCADA, Pedro. (2017). El estudio del turismo como sistema. $1^{\text {a }}$ ed. Méjico: Universidad del Caribe: Miguel Ángel Porrúa. 38 pp.

27. MOLINA, Sergio. (1991). Conceptualización del Turismo. Méjico: Limusa. 114 pp.

28. OCEGUERA, Juan Manuel, CASTILLO, Ramón y VARELA, Rogelio. (2009). Crecimiento Regional en Méjico: Especialización y Sectores Clave. Revista Latinoamericana de Economía, Vol. 40, №. 159. Pp. 62-84. http://dx.doi.org/10.22201/ iiec.20078951e.2009.159.14677

29. ONU. Organización de las Naciones Unidas (2015). Objetivos de Desarrollo Sostenible. Objetivos de Desarrollo: de los ODM, los ODS y La Agenda 2030: Objetivos de Desarrollo Sostenible de la Organización de Naciones Unidas. Disponible en Internet: https://onu. org.gt/objetivos-de-desarrollo/ Consultado: 19.05.2019. 
30. OMT. Organización Mundial del Turismo (2017). Panorama OMT del turismo internacional Disponible en Internet: https://www.e-unwto.org/doi/pdf/10.18111/9789284419043 Consultado: 19.05.2019.

31. OMT. Organización Mundial del Turismo (2017). Notas metodológicas de la base de datos de estadísticas de turismo. Madrid: UNWTO. 82 pp. Disponible en Internet: https:// www.e-unwto.org/doi/pdf/10.18111/9789284418589 Consultado: 18.05.2019.

32. OMT. Organización Mundial del Turismo (2019). Definiciones de turismo de la OMT. Madrid: UNWTO. 55 pp. Disponible en Internet: https://doi.org/10.18111/9789284420858

33. PÉREZ, Enrique, SÁNCHEZ, Alejandro y CUADRADO, Juan (2018). Distribución espacial del sector servicios en Méjico, 1999-2009. Especialización y diversificación desde una perspectiva macro- geográfica. Revista EURE-Revista de Estudios Urbano, Vol. 44, N ${ }^{\circ}$ 135. Pp. 215- 237. https://doi.org/10.4067/s0250-71612018000100215

34. RODRÍGUEZ, Vicente. (2005). Índice de especialización sectorial en los estados miembros de la Unión Europea en 2003. Boletín ICE Económico, Boletín Económico de ICE, N 2839. Pp. 27-33. Disponible en Internet: https://dialnet.unirioja.es/servlet/ articulo?codigo $=2051435$

Para citar este artículo:
ÁVILA, Marisol. (2020). Especialización del ecoturismo y turismo cultural en Méjico. Evaluación del desarrollo sostenible y económico. Teuken Bidikay, Vol. 11, № 16. Medellín: Politécnico Colombiano. Pp. 201-230. doi: $10.33571 /$ teuken.v11n16a9

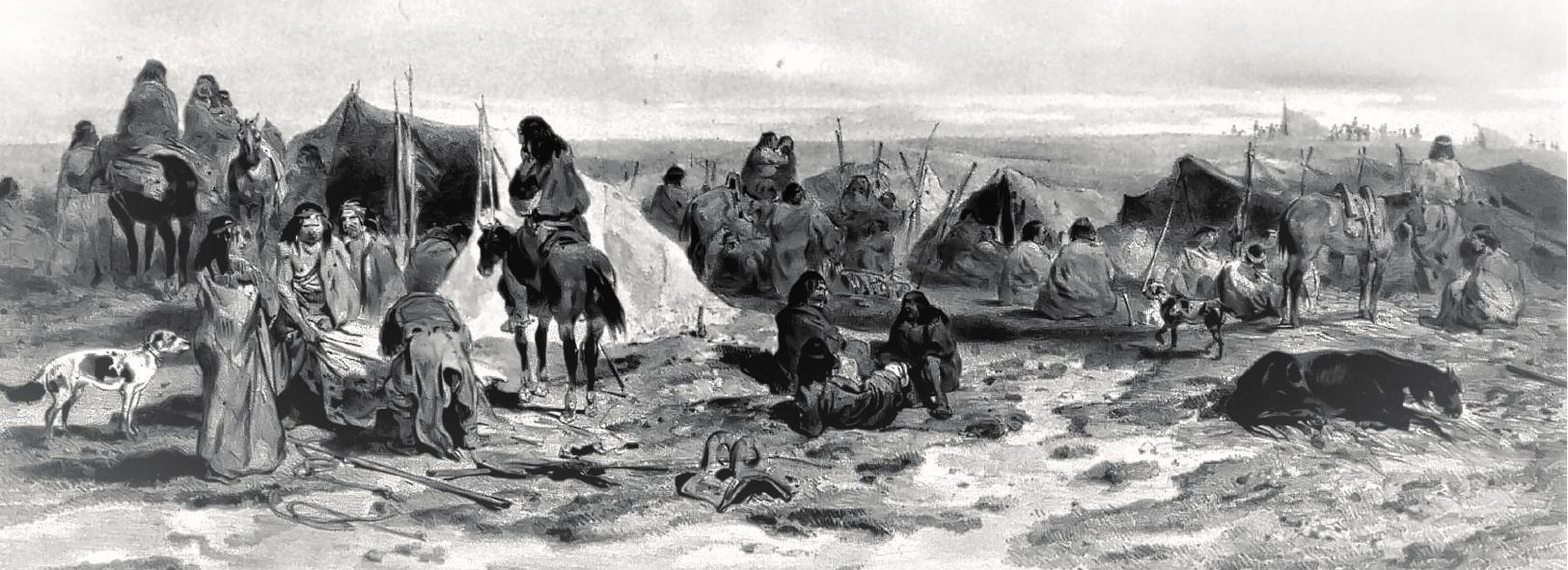

